\title{
Fire design method for concrete filled tubular columns based on equivalent concrete core cross-section
}

\author{
Carmen Ibañez ${ }^{\mathrm{a}}$, José V. Aguado ${ }^{\mathrm{b}}$, Manuel L. Romero ${ }^{\mathrm{c} *}$, Ana Espinos ${ }^{\mathrm{c}}$, Antonio Hospitaler ${ }^{\mathrm{c}}$ \\ a Departamento de Mecánica y Construcción \\ Universitat Jaume I, Castelló, Spain \\ b Institut de Recherche en Génie Civil et Mécanique (GeM) \\ Ecole Centrale de Nantes, France \\ c Instituto de Ciencia y Tecnología del Hormigón (ICITECH) \\ Universitat Politècnica de València, Spain \\ * corresponding author: mromero@mes.upv.es
}

\begin{abstract}
In this work, a method for a realistic cross-sectional temperature prediction and a simplified fire design method for circular concrete filled tubular columns under axial load are presented. The generalized lack of simple proposals for computing the crosssectional temperature field of CFT columns when their fire resistance is evaluated is evident. Even Eurocode 4 Part 1-2, which provides one of the most used fire design methods for composite columns, does not give any indications to the designers for computing the cross-sectional temperatures. Given the clear necessity of having an available method for that purpose, in this paper a set of equations for computing the temperature distribution of circular CFT columns filled with normal strength concrete is provided. First, a finite differences thermal model is presented and satisfactorily validated against experimental results for any type of concrete infill. This model considers the gap at steel-concrete interface, the moisture content in concrete and the
\end{abstract}


temperature dependent properties of both materials. Using this model, a thermal parametric analysis is executed and from the corresponding statistical analysis of the data generated, the practical expressions are derived. The second part of the paper deals with the development of a fire design method for axially loaded CFT columns based on the general rules stablished in Eurocode 4 Part 1-1 and employing the concept of room temperature equivalent concrete core cross-section. In order to propose simple equations, a multiple nonlinear regression analysis is made with the numerical results generated through a thermo-mechanical parametric analysis. Once more, predicted results are compared to experimental values giving a reasonable accuracy and slightly safe results.

Keywords: Concrete filled tubular column; Numerical model; Finite differences; Temperature prediction; Simple calculation procedure; Equivalent cross-section; Fire resistance; Eurocode 4.

\section{NOTATION}
$\mathrm{A} / \mathrm{V}$
Section factor
CFT
Concrete filled tube

CXXX-T-L-FF-EE (i.e. C159-6-3-30-0), where C stands for circular, XXX is the diameter in $\mathrm{mm}$, " $\mathrm{T}$ " the thickness in $\mathrm{mm}, \mathrm{L}$ the nominal length in meters, FF the nominal concrete strength in $\mathrm{MPa}$, and $\mathrm{EE}$ is the applied eccentricity.

$D \quad$ Diameter of the column

FC Fiber reinforced concrete

FRR Fire resistance rating

$f_{c} \quad$ Compressive cylinder strength of concrete at room temperature (test date)

$f_{y} \quad$ Yield strength of structural steel at room temperature 
Ibañez C, Aguado JV, Romero ML, Espinos A, Hospitaler A. Fire design method for concrete filled tubular columns based on equivalent concrete core cross-section. Fire Safety Journal. 2015; 78:10-23.

doi: 10.1016/j.firesaf.2015.07.009

$L \quad$ Length of the column

$l_{\theta} \quad$ Buckling length in the fire situation

RC Reinforced concrete

$T$

Temperature

$t$

Thickness of the steel tube

$\mu=N / N_{R d} \quad$ Axial load level

$\xi \quad$ Relative error 


\section{INTRODUCTION}

In recent years, the use of concrete filled tubular (CFT) columns has increased and concurrently, the interest of engineers and architects in the fire design of these composite columns has also augmented. In fire situation, CFT columns show a high resistance even when no external protection is used. The steel tube protects the concrete core from the direct exposure to fire and, in turn, the concrete infill delays the heating of the steel profile. Mechanical properties of both materials degrade as temperature increases, but steel loses its resistance faster than concrete. Determining with accuracy the cross-sectional temperature distribution when modeling a CFT column in fire is crucial, and moreover if a realistic fire resistance prediction is expected.

European code EN 1994-1-2 [1] in its Clause 4.3.5.1 establishes a general method to study the fire resistance of composite columns. This procedure takes into account the temperature dependent thermal and mechanical properties of the material but no recommendations are given regarding the calculation of the cross-sectional temperature field along time.

A simple calculation model explicitly for CFT sections in fire proposed in Annex $\mathrm{H}$ of the same code [1] indicates that the temperature distribution shall be calculated neglecting the thermal resistance at steel-concrete interface for simplicity and in accordance with Clause 4.4.2. This section provides a series of guidelines regarding thermal actions, variation of thermal properties with temperature and concrete moisture content for thermal response in advanced calculation models, which are only applied in specific situations when the actual behavior is required.

In summary, EN 1994-1-2 [1] does not provide any direct method to obtain the time dependent cross-sectional temperature distribution in a CFT column for the standard fire classes (R30, R60, R90 and R120). Designers are obliged to turn to 
numerical models or to implement complex methods available in published research works [5].

Thermal analysis is the first step to carry out when the whole response of a CFT column is analyzed. In the reviewed literature, some of the studies considered realistic features regarding the heat transfer process, such as the three-dimensional model presented by Espinos et al. [2] which took into account the gap at the steel-concrete interface and the water content of the concrete core; or the numerical model developed by $\mathrm{Lu}$ et al. [3] which assumed a heat contact conductance parameter to represent the gap between the two materials. But these works focused on models to study the global fire behavior of CFT columns. Computing the temperature distribution of the column was just an implicit step within the entire calculation. Therefore, they do not present any simple and specific procedure for computing the cross-sectional temperature.

With regard to studies dealing exclusively with the thermal analysis of CFT columns, just few publications can be located. A numerical method using the Green's function approach was developed by Wang et al. [4] for protected steel members and later it was extended by Wang and Tan [5] to solve the heat transfer problem in CFT columns. However, the concrete and steel properties were considered temperature independent, perfect contact between materials was assumed and also the presence of moisture in the concrete was neglected. These conservative assumptions made the method lose accuracy.

Another approach to solve the sectional heat transfer problem in CFT columns is employing finite differences. Hence, Lie [6] developed a formulation for circular CFT columns based on the methodology proposed by Dusinberre [7]. Again, perfect contact was assumed at steel-concrete interface. 
Although some realistic features were not considered, these works presented effective procedures to obtain temperature distribution at the cross-section of CFT columns. In spite of this, since no straightforward equations were provided, designers might find tedious and time-consuming implementing them in the daily practice.

Relating to fire design methods for CFT columns following the general rules of EN 1994-1-2 [1], some works can be found where the authors have treated the crosssectional thermal analysis step separately. Thus, researchers like Espinos et al. [8] proposed an effective design procedure as a result of an extensive parametric study carried out by means of their validated three-dimensional model [2]. However, this method assumed an equivalent temperature for the concrete core so the cross-sectional temperature distribution was no explicitly calculated. In the same line, Yu et al. [9] developed a simple calculation method for the fire resistance of CFT columns but again on the assumption of average temperatures for both steel tube and concrete core crosssections.

This work can be divided into two parts: on the one hand, practical expressions for computing the cross-sectional temperatures of circular CFT columns are developed; on the other hand, a simple design method for obtaining the fire resistance of axially loaded CFT columns is proposed.

Therefore, the outline of this paper is as follows. First, a finite differences method for solving the heat transfer problem is developed improving the initial approach of Dusinberre [7] by considering the effect of the gap conductance at steel-concrete interface and, in general, all the detected nonlinearities involved in the heat transfer process to obtain a response as realistic as possible. The finite differences method is valid for a wide range of concrete infill: plain, bar reinforced and steel fiber reinforced 
concrete of both normal and high strength. The thermal model is validated against experimental results showing good agreement.

Next, an extensive thermal parametric analysis is carried out in order to obtain a regression equation for calculating the cross-sectional temperature field. Although the thermal model developed has proven to be valid for protected and unprotected CFT columns with any type of concrete infill, as a first step, the parametric analysis and the proposed adjustment equations are specifically focused on unprotected circular CFT columns filled with normal strength concrete. In order to extend the current equations or to obtain new temperature expressions for other types of concrete infill, it is necessary to perform the pertinent parametric analysis taking into account the corresponding thermal properties.

The concept of equivalent concrete core cross-section at room temperature is exposed right after, since it is the starting point to develop the fire design method proposed, which is verified against experimental results.

Finally, a case of CFT column fire design is included to exemplify the use of the calculation procedure presented.

\section{HEAT TRANSFER MODEL}

The heat transfer model involves the calculation of the temperatures given by the fire curve to which the column is exposed and the determination of column crosssectional temperatures.

The model formulation is based on the finite differences method with an explicit scheme and follows the line proposed by Dusinberre [7]. Previously, Lie [6] had already taken as a basis the same approach to solve the heat transfer problem for circular CFT 
columns but ignoring the gap conductance that appears between the steel tube and the concrete core which clearly reduces the thermal response accuracy.

In this paper, only the expressions to obtain cross-sectional temperatures are presented since the derivation of these equations is explained with detail in previous works [7].

\section{Discretization of the section}

The nomenclature used by Lie [6] will be maintained in order to make easier any comparison between both formulations. Due to axisymmetric conditions, the heat transfer problem becomes unidirectional what simplifies the discretization of the section as well as the calculation process.

For each material, the division is made in equal increments of the radius as showed in Fig. 1. The number of subdivisions in the steel tube is $\left(M_{1}-1\right)$ and $\left(M_{2}-M_{1}+\right.$ 1) in the concrete core. The temperature is calculated for the target points which are placed at layer boundaries and represented by $P_{m}$ as it can be observed in Fig. 1. .

The main improvement with respect to the method presented by Lie [6] lies in the consideration of the existence of a gap conductance at the steel-concrete interface with the aim of obtaining a realistic thermal response.

Gap conductance is a phenomenon arising at the interface between two materials due to the loss of contact in almost the totality of the facing surfaces. When two solid materials remain in contact in a small number of points, the generated gaps can contain water steam characterized by a considerably lower thermal conductivity than the other solid materials. In a CFT column, due to the different thermal expansion coefficients, the clearance between the two contacting surfaces will increase as they progressively separate from each other. 
In order to represent this event, the node physically placed at the steel-concrete boundary is theoretically split into two nodes: one node belongs to the steel tube inner surface and the second node is located in the concrete core outer surface, Fig. 2. Thus, it is possible to consider the steel-concrete gap as a new layer of thickness zero characterized by a thermal conductance that reproduces the sudden drop of temperatures from the steel tube to the concrete core.

The thickness of all the layers in the steel tube is $\Delta \xi_{s}$, except for the layer at the steel-concrete boundary which is $1 / 2 \Delta \xi_{s}$ thick. The same occurs in the concrete core, while all the inner layers have a thickness of $\Delta \xi_{c}$, the layer at steel-concrete interface and the layer at the center of the column are $1 / 2 \Delta \xi_{c}$.

For deriving the next equations, an arc of 1 radian is used and the depth in the axial direction is taken as unity as pointed out by Dusinberre [7].

\subsection{CROSS-SECTIONAL TEMPERATURES}

In this work, the whole length of the column is supposed to be uniformly exposed to a fire. Just for description purposes, it is assumed that the fire evolution follows the standard fire curve ISO 834 [10][11]. Note that this curve can be replaced by the heating curve characterizing an actual fire or by another standard fire curve. ISO 834 is represented by the next expression:

$$
T_{f}^{j}=20+345 \log (8 \tau+1)
$$

where $\tau$ is the time in minutes and $T_{f}^{j}$ is the fire temperature, in ${ }^{\circ} \mathrm{C}$, at time $\tau=j \Delta \tau$.

For a CFT column, at time $\tau=(j+1) \Delta \tau$, the temperature at the different points of the section can be calculated as follows: 


\section{Equations for fire-steel boundary $(m=1)$}

$$
\begin{gathered}
T_{1}^{j+1}=T_{1}^{j}+\frac{2 \Delta \tau R_{s}}{\rho_{s}^{j} c_{p s}^{j}\left(R_{s}-\frac{\Delta \xi_{s}}{4}\right) \Delta \xi_{s}}\left\{\sigma \varepsilon_{f} \varepsilon_{p}\left[\left(T_{f}^{j}+273\right)^{4}-\left(T_{1}^{j}+273\right)^{4}\right]+\right. \\
\left.+h\left(T_{f}^{j}-T_{1}^{j}\right)\right\}-\frac{\Delta \tau\left(R_{s}-\frac{\Delta \xi_{s}}{2}\right)}{\rho_{s} c_{p s}^{j}\left(R_{s}-\frac{\Delta \xi_{s}}{4}\right) \Delta \xi_{s}{ }^{2}}\left[\left(k_{s}\right)_{1}^{j}+\left(k_{s}\right)_{2}^{j}\right]\left(T_{1}^{j}-T_{2}^{j}\right)
\end{gathered}
$$

where $T_{1}^{j+1}$ is the temperature at the surface of the steel tube at time $\tau=(j+1) \Delta \tau, R_{s}$ is the external CFT column radius; $\Delta \xi_{s}$ is the thickness of steel tube layers.; $\rho_{s}, c_{p s}$ and $k_{s}$ are the density, specific heat and conductivity of steel; $\varepsilon_{f}$ is the emissivity of the fire; $\varepsilon_{p}$ is the emissivity of the exposed surface (steel tube); $\sigma$ is the Stephan-Boltzmann constant; and $h$ is the coefficient of convective heat transfer.

\section{Equations for inside steel tube $\left(1<m<M_{1}-1\right)$}

To obtain the temperature at the inner layers of the steel tube the expression to be used is the next,

$$
\begin{aligned}
& T_{m}^{j+1}=T_{m}^{j}+\frac{\Delta \tau}{2 \rho_{s}^{j} c_{p s}^{j}\left[R_{s}-(m-1) \Delta \xi_{s}\right] \Delta \xi_{s}^{2}}\left\{\left[R_{s}-\left(m-\frac{3}{2}\right) \Delta \xi_{s}\right] .\right. \\
& \left.\cdot\left[\left(k_{s}\right)_{m-1}^{j}+\left(k_{s}\right)_{m}^{j}\right]\left(T_{m-1}^{j}-T_{m}^{j}\right)-\left[R_{s}-\left(m-\frac{1}{2}\right) \Delta \xi_{s}\right]\left[\left(k_{s}\right)_{m}^{j}+\left(k_{s}\right)_{m+1}^{j}\right]\left(T_{m}^{j}-T_{m+1}^{j}\right)\right\}
\end{aligned}
$$

where $T_{m}^{j+1}$ is the temperature at point $m$ inside the steel at time $\tau=(j+1) \Delta \tau$.

\section{Equations for steel-concrete boundary: Steel tube inner surface $\left(m=M_{1}-1\right)$}

As explained above, the contact between the steel tube and the concrete core is modeled in a realistic way by modeling the gap conductance at the steel-concrete interface.

The temperature at the steel tube inner surface at time $\tau=(j+1) \Delta \tau$ is given by: 


$$
\begin{aligned}
& T_{M_{1}-1}^{j+1}=T_{M_{1}-1}^{j}+\frac{\Delta \tau}{\rho_{s}^{j} c_{p s}^{j}\left[R_{s}-\left(M_{1}-\frac{9}{4}\right) \Delta \xi_{s}\right] \Delta \xi_{s}^{2}}\left\{\left[R_{s}-\left(M_{1}-\frac{5}{2}\right) \Delta \xi_{s}\right] .\right. \\
& \left.\cdot\left[\left(k_{s}\right)_{M_{1}-2}^{j}+\left(k_{s}\right)_{M_{1}-1}^{j}\right]\left(T_{M_{1}-2}^{j}-T_{M_{1}-1}^{j}\right)-2 h_{g a p} R_{c} \Delta \xi_{s}\left(T_{M_{1}-1}^{j}-T_{M_{1}}^{j}\right)\right\}
\end{aligned}
$$

where $h_{g a p}$ is the thermal gap conductance at steel-concrete interface. It is defined as the conductance of the separation layer appearing between the two components.

\section{Equations for steel-concrete boundary: Concrete core outer surface $\left(\boldsymbol{m}=M_{1}\right)$}

On the other hand, the temperature at the surface of concrete core in the steel-concrete boundary at time $\tau=(j+1) \Delta \tau$ is given by:

$$
\begin{aligned}
& T_{M_{1}}^{j+1}=T_{M_{1}}^{j}+\frac{\Delta \tau}{\left[\rho_{c}^{j} c_{p c}^{j}+\rho_{w}^{j} c_{p w}^{j} \phi_{M_{1}}^{j}\right]\left[R_{c}-\frac{\Delta \xi_{c}}{4}\right] \Delta \xi_{c}^{2}}\left\{2 h_{g a p} R_{c} \Delta \xi_{c}\left(T_{M_{1}-1}^{j}-T_{M_{1}}^{j}\right)-\right. \\
& \left.-\left(R_{c}-\frac{\Delta \xi_{c}}{2}\right)\left[\left(k_{c}\right)_{M_{1}}^{j}+\left(k_{c}\right)_{M_{1}+1}^{j}\right]\left(T_{M_{1}}^{j}-T_{M_{1}+1}^{j}\right)\right\}
\end{aligned}
$$

where $\rho_{c}, c_{p c}$ and $k_{c}$ are the density, specific heat and conductivity of concrete; $\Delta \xi_{c}$ is the thickness of concrete core layers; $\rho_{w}$ and $c_{p w}$ are the density and specific heat of water; $\phi$ is the concrete moisture content; and $R_{c}$ is the concrete core radius.

\section{Equations for inside concrete core $\left(M_{1}+1 \leq m<M_{2}\right)$}

For the interior points of the concrete core, except for the point located at the center of the concrete core cross-section, the temperature at time $\tau=(j+1) \Delta \tau$ can be determined by the next equation:

$$
\begin{aligned}
& T_{m}^{j+1}=T_{m}^{j}+\frac{\Delta \tau}{2\left[\rho_{c}^{j} c_{p c}^{j}+\rho_{w}^{j} c_{p w}^{j} \phi_{m}^{j}\right]\left[R_{c}-\left(m-M_{1}\right) \Delta \xi_{c}\right] \Delta \xi_{c}{ }^{2}} \cdot \\
& \cdot\left\{\left[R_{c}-\left(m-M_{1}-\frac{1}{2}\right) \Delta \xi_{c}\right]\left[\left(k_{c}\right)_{m-1}^{j}+\left(k_{c}\right)_{m}^{j}\right]\left(T_{m-1}^{j}-T_{m}^{j}\right)-\right. \\
& \left.-\left[R_{c}-\left(m-M_{1}+\frac{1}{2}\right) \Delta \xi_{c}\right]\left[\left(k_{c}\right)_{m}^{j}+\left(k_{c}\right)_{m+1}^{j}\right]\left(T_{m}^{j}-T_{m+1}^{j}\right)\right\}
\end{aligned}
$$




\section{Equations for the center of concrete core $\left(m=M_{2}\right)$}

The temperature at the center of the concrete core at time $\tau=(j+1) \Delta \tau$ is given by:

$$
T_{M_{2}}^{j+1}=T_{M_{2}}^{j}+\frac{2 \Delta \tau}{\rho_{c}^{j} c_{p c}^{j} \Delta \xi_{c}^{2}}\left[\left(k_{c}\right)_{M_{2}-1}^{j}+\left(k_{c}\right)_{M_{2}}^{j}\right]\left(T_{M_{2}-1}^{j}-T_{M_{2}}^{j}\right)
$$

\subsection{CONTENT OF MOISTURE IN THE CONCRETE CORE}

The effect of moisture in the concrete is taken into account by assuming that the initial volume of moisture in the concrete starts to evaporate when the temperature reaches $100^{\circ} \mathrm{C}$. During the evaporation all the heat provided is consumed in this process so that the temperature does not increase until the water has evaporated completely.

\section{INITIAL CONTENT OF MOISTURE}

The initial content of moisture expressed in volume and the volume of moisture evaporated during a period of time $\Delta \tau$ is given by:

\section{Steel-concrete boundary: Concrete core outer surface $\left(m=M_{1}\right)$}

For the external layer of the concrete core, the expressions are:

$$
V_{M_{1}}=2 \pi\left[R_{c}-\frac{\Delta \xi_{c}}{4}\right] \frac{\Delta \xi_{c}}{2} \phi_{M_{1}}=\pi\left[R_{c}-\frac{\Delta \xi_{c}}{4}\right] \Delta \xi_{c} \phi_{M_{1}}
$$

$$
\begin{aligned}
& \Delta V_{M_{1}}^{j}=\pi \frac{\pi \Delta \tau}{\rho_{w} \lambda_{w} \Delta \xi_{c}}\left\{2 \lambda R_{c} \Delta \xi_{c}\left(T_{M_{1}-1}^{j}-T_{M_{1}}^{j}\right)-\right. \\
& \left.-\left(R_{c}-\frac{\Delta \xi_{c}}{2}\right)\left[\left(k_{c}\right)_{M_{1}}^{j}+\left(k_{c}\right)_{M_{1}+1}^{j}\right]\left(T_{M_{1}}^{j}-T_{M_{1}+1}^{j}\right)\right\}
\end{aligned}
$$

\section{Inside concrete core $\quad\left(M_{1}+1 \leq m<M_{2}\right)$}

In the case of the inner regions of the concrete core, except for the point representing the central area, the equations are: 


$$
\begin{aligned}
& V_{m}=2 \pi\left[R_{c}-\left(m-M_{1}\right) \Delta \xi_{c}\right] \Delta \xi_{c} \phi_{m} \\
& \Delta V_{m}^{j}=\frac{\pi \Delta \tau}{\rho_{w} \lambda_{w} \Delta \xi_{c}}\left\{\left[R_{c}-\left(m-M_{1}-\frac{1}{2}\right) \Delta \xi_{c}\right]\left[\left(k_{c}\right)_{m-1}^{j}+\left(k_{c}\right)_{m}^{j}\right]\left(T_{m-1}^{j}-T_{m}^{j}\right)-\right. \\
& \left.-\left[R_{c}-\left(m-M_{1}+\frac{1}{2}\right) \Delta \xi_{c}\right]\left[\left(k_{c}\right)_{m}^{j}+\left(k_{c}\right)_{m+1}^{j}\right]\left(T_{m}^{j}-T_{m+1}^{j}\right)\right\}
\end{aligned}
$$

\section{Center of concrete core $\left(m=M_{2}\right)$}

Finally, for the concrete core central region, the next expressions are used:

$$
\begin{aligned}
& V_{M_{2}}=2 \pi \frac{\Delta \xi_{c}^{2}}{8} \phi_{M_{2}}=\pi \frac{\Delta \xi_{c}^{2}}{4} \phi_{M_{2}} \\
& \Delta V_{M_{2}}^{j}=\frac{\pi \Delta \tau}{2 \rho_{w} \lambda_{w}}\left[\left(k_{c}\right)_{M_{2}-1}^{j}+\left(k_{c}\right)_{M_{2}}^{j}\right]\left(T_{M_{2}-1}^{j}-T_{M_{2}}^{j}\right)
\end{aligned}
$$

This thermal analysis procedure was implemented in Matlab and it represents the first step of the fiber beam model developed by the authors for simulating the fire response of CFT columns. The description of the fiber beam model and its validation against experimental tests was presented in a previous publication [12]. The model proved to give very accurate times of fire resistance and to reproduce precisely the whole fire response of CFT columns along time.

\section{VALIDATION}

The model presented has been validated by contrasting its calculated crosssectional temperatures with experimental data. For this purpose, experimental results from tests carried out by the authors were used but also data from other experimental programs reported in the literature were employed. 


\subsection{EXPERIMENTAL TESTS FOR VALIDATION}

In order to validate the thermal model, data from two experimental campaigns were used. On the one hand, results from tests carried out by the authors and reported in previous works [13][14] were employed. All the CFT columns were tested at AIDICO (Instituto Tecnológico de la Construcción) in Valencia, Spain. The analyzed specimens comprised columns filled with normal and high strength concrete of different type infill: plain, bar reinforced and steel fiber reinforced concrete, and, in all cases, the aggregates were calcareous. These specimens were heated following the standard ISO-834 curve [10][11]. The main characteristics of these columns can be found in Table 1 .

On the other hand, data from tests performed by Lie and Chabot [15] were also used so that the validation process was not limited to comparison with own experimental results. The thermal response of twenty-three columns specimens tested at the National Research Council of Canada (NRCC) was simulated. These columns were filled with normal strength concrete, with both siliceous and calcareous aggregates. In these tests, the standard fire curve followed was the ASTM-E119 [16]. Table 2 resumes the main parameters of these specimens.

For those tests in which the moisture content was not reported, the following values were adopted. For CFT columns containing siliceous aggregates, a moisture content value of $3 \%$ in concrete weight was employed, since they seem to retain less humidity than concrete with calcareous aggregates, for which a value of $10 \%$ was applied. These values are included in EN 1994-1-2 [1] as the two limits recommended for composite structures, pointing out that the upper value may occur in hollow sections filled with concrete. When comparing with tested columns, these values showed, respectively, the best correlation as it was already mentioned in previous works [2][12]. 
The data extracted from the tests which was relevant for validation was the evolution of the steel tube and concrete core temperature along time for contrasting the temperature prediction; and the applied axial load and the FRR achieved by each specimen for the validation of the simple method proposed.

\subsection{MATERIAL PROPERTIES AT HIGH TEMPERATURES}

The temperature dependent thermal properties of the materials were considered.

\section{a) Concrete}

The thermal properties for concrete at elevated temperatures from EN 1992-1-2 [17] were adopted. For the thermal conductivity of concrete, the upper limit was adopted.

For high strength concrete, the thermal properties proposed by Kodur and Sultan [18] were implemented, since they proved to fit closely the test data.

\section{b) Steel fiber reinforced concrete}

When modeling the specimens filled with steel fiber reinforced normal strength concrete, the thermal properties at high temperatures developed by Lie and Kodur [19] [20] were used.

For specimens with steel fiber reinforced high strength concrete as infill, the relationships for thermal properties at high temperature presented by Kodur and Sultan [18] were adopted.

\section{c) Steel}

For structural steel, the temperature dependent thermal properties recommended in EN 1993-1-2 [21] were implemented. 


\subsection{THERMAL ANALYSIS PARAMETERS}

The main parameters of the heat transfer problem and the adopted values, according to EN 1991-1-2 [11] are the next:

- Coefficient of convective heat transfer at the exposed surface: $h=25 \mathrm{~W} / \mathrm{m}^{2} \mathrm{~K}$

- Configuration factor for radiation at the exposed surface: $\Phi=1$

- Stephan-Boltzmann constant: $\sigma=5.67 \cdot 10^{-8} \mathrm{~W} / \mathrm{m}^{2} \mathrm{~K}^{4}$

- $\quad$ Emissivity of the exposed surface (steel): $\varepsilon_{s}=0.7$

- Emissivity of the fire: $\varepsilon_{f}=1$

- Initial temperature: $\mathrm{T}_{0}=20^{\circ} \mathrm{C}$

In this case, a constant value of $200 \mathrm{~W} / \mathrm{m}^{2} \mathrm{~K}$ was employed for the gap conductance at the steel-concrete interface. This constant value has been employed by the authors in previous works for the validation of a CFT thermo-mechanical model [12] and it proved to give accurate responses. Besides, authors like Espinos et al. [2] and Ding and Wang [22] suggested the adoption of this value for representing the gap conductance.

In this model, radiation at steel-concrete interface was not explicitly considered. The three-dimensional numerical model developed by Espinos et al. [2] for CFT columns in fire took into account the gap radiation by assuming an emissivity value of 0.7 for both materials. However, comparison of the temperature predictions obtained with the model here presented with those given by the 3D model showed an excellent agreement and confirmed the absence of significant differences in their predictions [12]. Thus, for simplicity it is assumed that, in this practical situation, the radiation across the gap can be neglected. 
Depending on the case analyzed, the exposed surface of the CFT column is heated following the corresponding standard fire curve or the furnace temperature-time curve if the deviation was very pronounced.

With regard to the discretization of the section in the thermal analysis, for each specimen, the number of layers was established so that for the hollow steel section the layer was not more than $10 \mathrm{~mm}$ thick which implied to considered one or two layers.

In the case of the concrete core, the number of layers was varied to obtain a size close to $20 \mathrm{~mm}$ which is recommended for thermal analysis and typical size used in other models [2][12].

\subsection{THERMAL RESPONSE OF CFT COLUMNS}

As an example, Fig. 3 shows the comparison between experimental data and predicted temperatures for two of the specimens analyzed. As it can be observed, the calculated temperatures along the cross-section show a good agreement with the experiments. Data results reported in literature include not only the evolution of the steel tube surface temperature (point $\mathrm{T} 1$ ) but also the temperature registered by thermocouples located at the inner of concrete core (point T2).

Nevertheless, it is worthy to mention that a little deviation between actual and calculated temperatures exists around temperatures of $100^{\circ} \mathrm{C}$. This discrepancy lies in how the moisture consumption was represented. As described above, it was modeled as a straightforward procedure based on employing all the heat applied in the evaporation of the water in the concrete once that temperature is reached.

When comparing the temperature-time curve given by the equation with the registered during the experiments, the reference section where the thermocouples were 
installed was located mid-height of the column. Normally, this is the most deformed part of the column after a fire test.

Another parameter of validation was the temperature at time of failure. The contrast was made between the measured steel tube surface temperature at failure and the one given by the model at that time. As it can be checked in Fig. 4a, the agreement between test data and model temperatures for all the specimens analyzed is remarkably good with mean error value of 1.00 and a standard deviation of 0.06 .

\subsection{EFFECT OF THE GAP CONDUCTANCE AT STEEL-CONCRETE INTERFACE}

Fig. 3 shows, for two of the cases studied, the comparison of the test temperatures with the results obtained under two different thermal contact models of the steelconcrete interface: perfect contact and gap conductance.

For the temperatures measured in the steel tube, the response given under the assumption of perfect contact lays below the test temperatures during most of the time. This behavior is due to the fact that no resistance opposes to the heat flow when crossing the steel-concrete boundary. The easier the heat flows through the section, the lower the temperatures achieved by the steel tube and the higher the temperatures in the concrete core.

Compared to the response obtained when a gap conductance is modeled at steelconcrete interface, this response is unrealistic and not conservative since it supposes that the steel tube reaches lower temperatures than the ones registered in the tests, leading to a less degradation of the material and resulting in higher fire resistance times predictions. 


\section{EQUATIONS FOR CROSS-SECTIONAL TEMPERATURE FIELD}

An extensive thermal parametric analysis, based on the one presented by the authors [8] in previous work, was carried out in order to generate data enough to obtain an accurate formulation by means of a nonlinear regression analysis. This parametric analysis covered section external diameters ranging from 139 to $508 \mathrm{~mm}$ combined with the minimum and maximum commercially available values of steel tube thicknesses for each case. The geometry of the analyzed composite sections can be found in Table 3 .

For each specimen, the analysis lasted $180 \mathrm{~min}$ so all the standard fire classes were covered (form R30 to R120) and data of the cross-sectional temperature distribution was registered every minute. The concrete core of the CFT columns included in the thermal parametric analysis was considered to be normal strength concrete with a moisture content of $3 \%$ for all the cases. A total of 48 cases were analyzed.

The set of practical equations here presented was obtained following the wellknown procedure developed by Wickström [23] who provided a simple method for estimating the temperature distribution in fire exposed concrete members. In contrast to this research, Wickström did not consider either the temperature dependent thermal properties of the materials or the concrete moisture content.

The equations proposed for the temperature distribution in the steel tube and in the concrete core of a circular CFT column cross-section had the following shape:

$\theta_{a}=\theta_{\text {room }}+\Delta \theta_{a}=\theta_{\text {room }}+\theta_{f} \cdot \eta_{s} \cdot \eta_{a} \nless \theta_{\text {room }}$

$\theta_{c}=\theta_{\text {room }}+\Delta \theta_{c}=\theta_{\text {room }}+\Delta \theta_{a} \cdot \eta_{c}=\theta_{\text {room }}+\theta_{f} \cdot \eta_{s} \cdot \eta_{a} \cdot \eta_{c} \nless \theta_{\text {room }}$ 
where $\theta_{a}$ is the steel tube temperature; $\theta_{\text {room }}$ accounts for room temperature $\left(20^{\circ} \mathrm{C}\right.$ in this case); $\Delta \theta_{a}$ is the steel tube temperature rise; $\theta_{f}$ represents the fire temperature rise; $\eta_{s}$ is the factor accounting for the temperature drop at the boundary layer; $\eta_{a}$ considers the temperature variation in the steel tube; and $\eta_{c}$ is the ratio between the temperature rise of a concrete core inner point $\Delta \theta_{c}$ and the steel tube temperature rise $\Delta \theta_{a}$. These terms can be identified in Fig. 5 where the temperature profile at a certain time is plotted in a longitudinal cut of a CFT column.

A multiple nonlinear regression analysis was executed to define every term of the proposed expressions and, finally, they were defined as follows:

$\theta_{f}=345 \log (8 R+1)$

$\eta_{s}=1-3.38 R^{-0.18}$

$\eta_{a}=1-\left[0.155 R^{0.58}+t^{-0.1}\right]$

$\eta_{c}=1-\left[0.073 \ln \left(\frac{r_{\text {int }}}{r_{\text {int }}-r}\right)+0.63 \cdot \frac{\left(r_{\text {int }}-r\right)^{0.23}}{R^{0.03}}-100 \frac{\left(r_{\text {int }}-r\right)^{0.41}}{r_{\text {int }}{ }^{1.79}}-0.318 R^{0.21}\right]$

where $\mathrm{R}$ is the fire exposure time in minutes; $\mathrm{t}$ is the steel tube wall thickness in $\mathrm{mm}$; $r_{i n t}$ is the concrete core radius in $\mathrm{mm} ; \mathrm{r}$ is the radius in $\mathrm{mm}$ which indicates the position in the concrete core where the temperature is calculated.

For the steel tube, a lumped capacitance model was adopted so that the variation of the temperature through the thickness of the steel tube wall is negligible.

In order to assess the accuracy of the proposed equations, the approach for the assessment of the accuracy of simplified methods proposed by CEN-Horizontal Group 
[24] was employed. The mentioned assessment method set the next criteria to check the acceptability of a simplified method:

- Calculation results shall not be on the unsafe side by more than the $15 \%$ of the reference value.

- A maximum of $20 \%$ of the individual calculation results shall be on the unsafe side.

- The mean value of all percentage differences shall be on the safe side.

Therefore, the equations here proposed were obtained so that their calculated values accomplish with these criteria.

In Fig. 6 the prediction given by these equations for the steel tube and inner points of the concrete core at different fire exposure times are compared to the values calculated by means of the thermal model described in section 3. In Fig. 6a and Fig. 6b, it can be observed that the point cloud lays mainly in the inner part of the deviation boundaries. Besides, both graphs show some points that exceed the boundaries, but always placed on the safe side.

The linear regression equation and its coefficient of determination $\mathrm{R}^{2}$ for the temperature prediction can be found in these graphs. In the case of steel tube temperature prediction the error mean value was $1.01(\sigma=0.09)$ and for the concrete core $1.18(\sigma=0.28)$, both safe values.

In addition, another significant parameter was studied. The temperature at failure given by the proposed equation is compared with the available test data in Fig. 4b. The agreement showed is excellent as can be checked in the graph where in most of the cases the predictions are safe and always lying in between the limits.

Fig. 7 shows the whole thermal response along time given by the proposed equations jointly with the experimental data and the temperatures calculated by the finite differences thermal model. It is observed the reasonable accuracy of the set of 
formula to predict the evolution of the temperatures along time for both the steel tube and the concrete core.

\section{FIRE DESIGN METHOD FOR AXIALLY LOADED CFT COLUMNS}

The equations provided in the previous section are very useful to obtain the crosssectional thermal distribution when the fire design methods available in EN 1994-1-2 [1] are employed. In these cases, the concrete core is divided into concentric layers and the temperature of each one is calculated separately which can result time-consuming.

However, in the daily practice it is not usually required to generate the crosssectional temperature field and the thermal analysis is a mere phase to obtain the fire resistance of the column.

Working in this line, it is possible to take a step forward to develop a design method for CFT columns in fire where the cross-sectional temperature field is not explicitly calculated. Besides, taking as a starting point the proposed thermal expressions does not produce loss of accuracy since the effect of the realistic considerations (such as the gap conductance at steel-concrete interface, the concrete moisture content of concrete and the temperature dependent thermal properties of the materials) is implicitly taken into account.

\subsection{EQUIVALENT CONCRETE CORE CROSS-SECTION}

The equivalent concrete core cross-section of a circular CFT column for a given fire exposure time is a concrete core cross-section at room temperature whose contribution to the buckling fire resistance of a CFT column is equivalent to the influence of the original concrete core cross-section subjected to the corresponding temperature field. 
The calculation method presented hereafter follows the general rules of the simplified method of Clause 6.7 .3 of EN 1994-1-1 [25] for the design of composite columns at room temperature. The external tube maintains its initial dimension and is made of a material representing the actual degraded steel for the given fire exposure time. However, the concrete core cross-section is represented by the equivalent concrete core cross-section with ambient temperature mechanical properties.

This procedure is conceptually similar to the simplified method proposed in Annex B.1 of EN 1992-1-2 [17] for reinforced concrete members exposed to fire. According to EN 1992-1-2's approach, the cross-section size suffers a general reduction with respect to the fire damaged area at the concrete surface. This method, generally known as " $500^{\circ} \mathrm{C}$ isotherm method", comprises the no contribution to the load bearing capacity of the member of that external area of concrete whose temperature is higher than $500^{\circ} \mathrm{C}$. On the contrary, the inner area of concrete with temperatures lower than $500^{\circ} \mathrm{C}$ retains its original mechanical properties.

In the case of CFT columns cross-sections, due to the combination of different steel tube thicknesses jointly with different column external diameters, it cannot be found a unique isotherm which determines the concrete core area contributing to the load bearing capacity. Therefore, this area will be determined by means of the radius of the equivalent concrete core cross-section which will be obviously dependent on the geometrical characteristics of the composite section and the fire exposure time. It is obtained through the procedure exposed below.

In the method proposed, the plastic resistance to axial compression of the section in the fire situation is calculated as follows:

$N_{f i, p l, R d}=A_{a} \cdot f_{a, \theta}+A_{c, e q} \cdot f_{c}$ 
and the effective flexural stiffness is obtained:

$(E I)_{f i, e f f}=E_{a, \theta} \cdot I_{a}+K_{e} \cdot E_{c} \cdot I_{c, e q}$

where $A_{a}$ and $I_{a}$ are the area and second moment of area respectively of the steel tube cross-section; $f_{a, \theta}$ is the steel strength at the temperature $\theta ; E_{a, \theta}$ is the modulus of elasticity of steel at the temperature $\theta ; A_{c, e q}$ and $I_{c, e q}$ are the equivalent area and equivalent second moment of area correspondingly of the concrete core cross-section; $f_{c}$ is the concrete strength at room temperature; $K_{e}$ is a correction factor that should be taken as 0.6 ; and $E_{c}$ is the secant modulus of concrete at room temperature. In Fig. 8a is shown the cross-section calculation scheme considered in the developed method.

In this approach, the confinement in the composite section is not considered and therefore, the increase of concrete compressive strength caused by this phenomenon is neglected.

For concrete, the mechanical properties at room temperature are adopted. However, for structural steel, mechanical model for high temperatures given in EN 1993-1-2 [21] are used.

On the other hand, according to EN 1994-1-2 [1], in order to analyze the fire resistance of a CFT column, each element of the composite section is divided into several layers. For the steel tube, $A_{a, \theta}$ and $I_{a, \theta}$ account for the area and second moment of area of one layer at temperature $\theta$. For the concrete core, $A_{c, \theta}$ is the area and $I_{c, \theta}$ represents the second moment of area at temperature $\theta$ of one layer. Assuming that for the steel tube just one layer is considered, the cross-section scheme used for calculation purposes is the one presented in Fig. 8b.

Therefore, the plastic resistance in fire for the composite section is equal to: 
$N_{f i, p l, R d}=A_{a, \theta} \cdot f_{a, \theta}+\sum_{m} A_{c, \theta} \cdot f_{c, \theta}$

and the effective flexural stiffness is calculated as follows:

$(E I)_{f i, e f f}=E_{a, \theta} \cdot I_{a, \theta}+\sum_{m} E_{c, \theta} \cdot I_{c, \theta}$

Therefore, the radius of the equivalent concrete core cross-section can be obtained following two different methods:

- Plastic resistance method

Since the term referring the steel tube remains equal, the equivalent area of concrete core which produces the same plastic resistance than the original composite section submitted to fire is given by

$\sum_{m} A_{c, \theta} \cdot f_{c, \theta}=A_{c, e q} \cdot f_{c}$

from where $r_{c, e q, A}$ is obtained.

- Effective flexural stiffness method

Once more, given that the part corresponding to the steel tube does not vary, the second moment of area which produces the same flexural stiffness is:

$\sum_{m} E_{c, \theta} \cdot I_{c, \theta}=K_{e} \cdot E_{c} \cdot I_{c, e q}$

and from this equation, $r_{c, e q, E I}$ is directly calculated.

In each case, the equivalent concrete core radius will be given by $r_{c, e q}=$ $\min \left\{r_{c, e q, A}, r_{c, e q, E I}\right\}$ since it will be the most restrictive value.

The previous equations were applied within the parametric analysis executed and for each section considered, $r_{c, e q}$ was obtained. In most cases, it was the plastic 
resistance approach the one producing the most restrictive values but particularly for the two smallest diameters, the flexural stiffness method gave smaller values of $r_{c, e q}$.

It is worthy to mention that, once the equivalent concrete core cross-section at room temperature is calculated with the predicted $r_{c, e q}$, all the related geometrical and mechanical characteristics change as a consequence, including the relative slenderness of the column used for the calculation of the reduction coefficient for buckling.

Once this step was completed, a nonlinear regression analysis was done. The next expression, that gives the $r_{c, e q}$ as a function of the section geometry and the fire exposure time R, was obtained:

$r_{c, e q}=r_{i n t}+23\left(\frac{A}{V}\right)^{-0.01}-10 R^{0.45} \nless 0$

Fig. 9 shows the comparison between the values of $r_{c, e q}$ calculated by the model and the ones given by the expression proposed. It can be observed that the predictions given by the expression have a high accuracy, with a safe mean error of $1.09(\sigma=0.22)$. The error is calculated by:

$$
\xi_{r}=1-\frac{r_{c, e q E Q U A T I O N}-r_{c, e q M O D E L}}{r_{c, e q ~ M O D E L}}
$$

\subsection{BUCKLING CORRECTION FACTOR}

Once the equivalent concrete core cross-section can be calculated, the next steps are executed. The relative slenderness $\bar{\lambda}_{\theta}$ at high temperatures is given by:

$\bar{\lambda}_{\theta}=\sqrt{\frac{N_{f i, p l, R}}{N_{c r}}}$

where $N_{c r}$ is the elastic critical normal force calculated as follows: 
$N_{c r}=\frac{\pi^{2}(E I)_{f i, e f f}}{l_{\theta}^{2}}$

In the calculation model here proposed, the value of the fire resistance of a CFT column in axial compression is calculated as follows:

$N_{f i, R d}=\eta_{\text {buckling }} \cdot \chi \cdot N_{f i, p l, R d}$

where $\chi$ is the reduction coefficient for the relevant buckling mode given in EN 1994-11 [25], which in this case corresponds to buckling curve "a"; and $\eta_{\text {buckling }}$ is the buckling correction factor to account for the influence of second order effects at high temperatures. As it can be observed, the simple method proposed employs the buckling curve "a" for calculation. The development of a new buckling curve is not considered in the method, just the adoption of a correction factor.

In order to define the shape of the buckling correction factor, the values of the normal force given a thermo-mechanical parametric analysis executed using the fiber model presented in [12] were used. The CFT column sections employed in the analysis were the ones specified in section 4. All the specimens were assumed to have a compressive strength of $30 \mathrm{MPa}$ for the concrete and a yield strength of $355 \mathrm{MPa}$ for the steel. For each cross-section, different values of slenderness were considered $(0.3$, $0.5,1,1.5$ and 2) and calculated according to EN 1994-1-1 [25]. Once more, analysis results were obtained for the four standard fire resistance classes (R30, R60, R90 and R120) for the 176 cases studied. In Table 3, the variables studied and the values considered which set the simple method applicability limits can be found.

In the thermo-mechanical parametric analysis, the procedure to obtain the fire buckling resistance of each column was the next. First, each one of the specimens was 
analyzed under different load levels to obtain the corresponding FRR. These applied loads were defined as a percentage of the room temperature buckling axial resistance, ranging from 0 to $90 \%$ to cover a wide range of FRR values.

Once the $\mathrm{N}_{\mathrm{fi}, \mathrm{Rd}}-\mathrm{FRR}$ curve is obtained for each column, the fire buckling resistance, $\mathrm{N}_{\mathrm{fi}, \mathrm{Rd}}$, at $\mathrm{R} 30, \mathrm{R} 60, \mathrm{R} 90$ and $\mathrm{R} 120$ minutes is calculated by linear interpolation.

The fiber model used for the parametric analysis performs a simple sequentially coupled thermal-stress analysis [12]. Two steps can be differenced. First, a thermal analysis is carried out to compute the temperature field of the columns by means of the finite differences method here presented and subsequently, a mechanical problem is solved to obtain the structural response. The specimen is loaded in the first calculation step and the load remains constant during the whole analysis.

The geometric imperfection due to the manufacturing process of the columns was taken into account by simulating the first buckling mode shape of a pinned-pinned column which exhibits a sinusoidal shape. The value adopted was L/1000 which is used by most of researchers and produces accurate results [12].

For each specimen analyzed, the buckling correction was calculated by:

$\eta_{\text {buckling }}=\frac{N_{f i, R d, M O D E L}}{\chi \cdot N_{f i, p l, R d, P R E D I C T E D}}$

With the set of buckling correction factor data, a statistical study was implemented. The possibility of assigning a unique value to the buckling correction factor was rejected since the analysis showed that the data was strongly dependent on the different geometrical variables $\left(l_{\theta} / D, A / V, D / t\right)$ that play an important role in this 
problem. Therefore, an expression which is function of the different variables was proposed. The equation is composed by the product of three partial coefficients:

$\eta_{\text {buckling }}=\eta_{l_{\theta} / D} \cdot \eta_{A / V} \cdot \eta_{D / t}$

Once the intensity of the effect that each variable has on the buckling correction factor was studied by means of a correlation analysis, a multiple nonlinear regression analysis was carried out. The shape proposed for each of the terms multiplying was:

$\eta_{l_{\theta} / D}=\left[a+b \cdot\left(l_{\theta} / D\right)^{c}\right]$

$\eta_{A / V}=\left[d+e \cdot(A / V)^{f}\right]$

$\eta_{D / t}=\left[g+h \cdot(D / t)^{i}\right]$

When the influence of the relative slenderness at room temperature on the buckling correction factor was studied, it was detected the convenience of developing two different buckling correction factors: one for the specimens with $\bar{\lambda} \leq 0.5$ and another one for the cases with $\bar{\lambda}>0.5$.

For cases with $\bar{\lambda} \leq 0.5$ (stub columns):

$$
\begin{aligned}
& \eta_{l_{\theta} / D}=\left[-4.16+4.208 \cdot\left(l_{\theta} / D\right)^{-0.003}\right] \\
& \eta_{A / V}=\left[0.13+9.8 \cdot(A / V)^{1.6}\right] \\
& \eta_{D / t}=\left[266+0.26 \cdot(D / t)^{1.5}\right]
\end{aligned}
$$

For cases with $\bar{\lambda}>0.5$ (slender columns):

$$
\eta_{l_{\theta} / D}=\left[0.72+0.008 \cdot\left(l_{\theta} / D\right)^{1.322}\right]
$$




$$
\begin{aligned}
& \eta_{A / V}=\left[0.67+7.4 \cdot(A / V)^{1.81}\right] \\
& \eta_{D / t}=\left[0.52+0.11 \cdot(D / t)^{-0.03}\right]
\end{aligned}
$$

Finally, the equations presented above are applied to all the cases covered in the parametric analysis in order to obtain the values of the buckling resistance in fire situation. For each specimen, the predicted value was compared to the numerical value and the error was computed using the next expression:

$\xi_{N, f i}=1-\frac{N_{f i, R d, P R E D I C T E D}-N_{f i, R d, M O D E L}}{N_{f i, R d, M O D E L}}$

In order to check the accuracy of the simple method proposed, the criteria of the assessment proposal made by CEN-Horizontal Group Fire [24] were again adopted.

The mean value of the error is equal to 1.07 which lies on the safe side $(\sigma=0.16)$. In Fig. 9, the error is plotted for the different values of relative slenderness at room temperature. According to CEN-Horizontal Group Fire [24], it can be observed that the simplified method produces values whose deviations with respect to the model predictions are concentrated above the $15 \%$ limits.

In Fig. 11 the comparison between predicted and numerical values of $\mathrm{N}_{\mathrm{fi}, \mathrm{Rd}}$ is plotted. Due to the wide range of fire buckling resistances two graphs are provided, being Fig. 11b an enlarged view of the shaded area marked in Fig. 11a.

This figure complements the information provided by Fig. 10 since it allows the observation of the regression line and its coefficient of determination $\mathrm{R}^{2}$ as recommended by CEN-Horizontal Group Fire [24]. 


\subsection{STEP BY STEP CALCULATION PROCEDURE}

In order to clarify the use of the proposed calculation procedure, the step by step method is described below:

1) Determine the effective length of the column, $l_{\theta}$, the section factor $A / V$ and the $D / t$ ratio.

2) Calculate the steel tube temperature $\theta_{a}$ by eq. (14) and the radius of the equivalent concrete core section $r_{c, e q}$ by eq. (26).

3) Obtain the cross-sectional plastic resistance using eq. (20) and temperature dependent steel mechanical properties from EN 1993-1-2 [21] .

4) Calculate the effective flexural stiffness using eq. (21) and temperature dependent steel mechanical properties from EN 1993-1-2 [21] .

5) Compute the Euler buckling load by means of eq. (29) and the relative slenderness in fire using eq. (28).

6) Calculate the buckling reduction coefficient from buckling curve "a" as it is indicated in EN 1994-1-1 [25].

7) Calculate the buckling correction factor by means of eq. (32)

8) Obtain the axial buckling load in the fire situation by means of eq. (30).

\subsection{COMPARISON OF CALCULATED PREDICTIONS WITH TESTS}

Predictions given by the proposed method were compared to experimental data from actual fire tests. The calculation procedure here presented is valid for circular CFT columns filled with unreinforced normal strength concrete and under axial load. Therefore, only data from experimental programs that obey these conditions was contrasted. 
For this purpose, both results of tests carried out by the authors [13] and data from tests found in the literature [15] were used. A description of these tests can be found in section 3 and more details in Table 1 and Table 2. For this validation, test data from [14] cannot be employed since all the specimens included in this program were eccentrically loaded.

The comparison in terms of axial buckling load is presented in Fig. 12 where it can be observed that the accuracy of the proposed method is satisfactory and that its predictions are generally conservative

\section{DESIGN EXAMPLE}

In this section, a case of CFT column fire design is included to exemplify the use of the fire design method presented.

The unprotected CFT column used in this example is $3400 \mathrm{~mm}$ long, has an external diameter of $193.7 \mathrm{~mm}$ and a wall steel tube thickness of $16 \mathrm{~mm}$. The compressive strength of the concrete core is $30 \mathrm{MPa}$ and for steel, a yield strength of $355 \mathrm{MPa}$ is considered.

In this example, the axial buckling load in the fire situation for a column placed in an intermediate floor for a fire exposure time of $30 \mathrm{~min}(\mathrm{R} 30)$ is asked to be determined.

First, the geometric parameters are calculated:

$l_{\theta}=L_{e i}=0.5 \cdot L=0.5 \times 3400=1700 \mathrm{~mm}(\mathrm{EN} \mathrm{1994-1-2} \mathrm{establishes} \mathrm{that} \mathrm{the} \mathrm{buckling}$ length in fire of a column in an intermediate story is $L_{e i}$ defined as 0.5 times the original length)

$$
\begin{aligned}
& A / V=4 / D=4 / 193.7=0.02065 \mathrm{~mm}^{-1} \\
& D / t=193.7 / 16=12.11 \\
& l_{\theta} / D=1700 / 193.7=8.77
\end{aligned}
$$


Next, the steel tube temperature is computed:

$$
\begin{aligned}
& \theta_{a}=\theta_{\text {room }}+\theta_{f} \cdot \eta_{s} \cdot \eta_{a}=20+345 \log (8 \times 30+1) x\left(1-3.38 \times 30^{-0.18}\right) x \\
& x\left(1-0.155 \times 30^{0.58}-16^{-0.1}\right)=616.76^{\circ} \mathrm{C}
\end{aligned}
$$

And also the $r_{c, e q}$ :

$r_{c, e q}=80.85+23 \times 0.02065^{-0.01}-10 \times 30^{0.45}=58.55 \mathrm{~mm}$

For a steel tube temperature of $616.76{ }^{\circ} \mathrm{C}$, the reduction factors for the yield strength $k_{y, \theta}$ and the modulus of elasticity $k_{E, \theta}$ of the steel are taken from table 3.2 of EN-1994-1-2 by linear interpolation:

$$
k_{y, 946.42}=0.4297 \quad k_{E, 946.42}=0.2798
$$

Once this is done, the cross-sectional plastic resistance and the effective flexural stiffness can be calculated.

$N_{f i, p l, R d}=A_{a} \cdot f_{a, \theta}+A_{c, e q} \cdot f_{c}=$ 8932.2 $\mathrm{mm}^{2} x 0.4297 x 355 \mathrm{MPa}+10769.7 \mathrm{~mm}^{2} x 30 \mathrm{MPa}=1685640.1 \mathrm{~N}=$ $1685.64 \mathrm{kN}$

$(E I)_{f i, e f f}=E_{a, \theta} \cdot I_{a}+K_{e} \cdot E_{c} \cdot I_{c, e q}=0.2798 \times 210000 \times 35542569.5+$ $0.6 \times 32836.6 \times 9231981.14=2.2703 \times 10^{12} \mathrm{~N} \cdot \mathrm{mm}^{2}$

Next, the Euler buckling load and the relative slenderness of the equivalent column can be calculated:

$N_{c r}=\pi^{2}(E I)_{f i, e f f} / L^{2}=\pi^{2} \times 2.2703 \times 10^{12} / 1700^{2}=7753274.35 \mathrm{~N}=7753.27 \mathrm{kN}$ 
$\bar{\lambda}_{\theta}=\sqrt{N_{f i, p l, R} / N_{c r}}=\sqrt{1685.64 / 7753.27}=0.466$

According to EN 1994-1-1, the reduction coefficient $\chi$ obtained from buckling curve "a" for the given relative slenderness is 0.934 .

Finally, the buckling correction factor should be obtained by means of eq. (32). In this case, for this column (with an initial room temperature relative slenderness of 0.74 ), the partial terms are given by eq. (39)-(41):

$$
\begin{aligned}
\eta_{\text {buckling }}=\eta_{L / D} \cdot \eta_{A / V} \cdot \eta_{D / t}= & \\
= & \left(0.72+0.008 \times 8.77^{1.322}\right) \times\left(0.67+7.4 \times 0.02065^{1.81}\right) \times(0.52 \\
& \left.+0.11 \times 12.11^{-0.03}\right)=0.3625
\end{aligned}
$$

Therefore, the fire resistance to the column to axial compression for a fire exposure time of $\mathrm{R} 30$ is:

$N_{f i, R d}=\chi \cdot \eta_{\text {buckling }} \cdot N_{f i, p l, R d}=0.934 \times 0.3625 \times 1685.64=570.48 \mathrm{kN}$

\section{SUMMARY AND CONCLUSIONS}

On a first stage, this paper provided a set of practical expressions for obtaining the cross-sectional temperatures of circular CFT columns. A realistic finite differences thermal model for circular CFT columns with any type of infill was presented. The consideration of the effects of the gap conductance at steel-concrete interface by characterizing the separation layer by a thermal conductance was crucial and produced much more realistic predictions than assuming perfect contact.

The thermal model was validated against experimental data and it showed remarkably good agreement with tests results in terms of temperature versus time and high accuracy when temperatures at time of failure were contrasted. 
With this model a thermal parametric analysis was performed and through the subsequent statistical study the proposed equations were extracted. Equation predictions were also compared to experimental results showing reasonable accuracy given the irregularities that may arise when measuring temperatures during a test. These expressions allow designers to compute easily the temperature distribution in the composite section without the need of implementing complex thermal models.

The paper also proposed a design method for obtaining the fire resistance of axially loaded circular CFT columns based on general rules of EN 1994-1-1. The concept of room temperature equivalent concrete core cross-section was introduced and used in the development of the simplified method where also a new buckling correction factor was considered. Numerical results generated through an extensive thermomechanical parametric analysis were used to carry out a multiple nonlinear regression analysis and, as a result, the expression for the buckling correction factor was built.

The equations for temperature calculation as well as the one for obtaining the buckling fire resistance were assessed following the guidelines included in CENHorizontal Group Fire for checking the accuracy of simplified methods.

The simple method predictions were compared to experimental data and they showed to be slightly conservative. In general, it can be said that the method produces satisfactory values of the fire resistance.

\section{ACKNOWLEDGEMENTS}

The authors would like to express their sincere gratitude to the Spanish Ministry of Economy and Competitivity for the help provided through the project BIA201233144, and to the European Community for the FEDER funds. 


\section{REFERENCES}

[1] CEN. EN 1994-1-2, Eurocode 4: Design of composite steel and concrete structures, Part 1.2: General rules - Structural fire design. Brussels, Belgium: Comité Européen de Normalisation; 2005.

[2] Espinos A, Romero M, Hospitaler A. Advanced model for predicting the fire response of concrete filled tubular columns. Journal of constructional steel research 2010; 66(8-9):1030-1046.

[3] Lu H, Zhao X, Han L. Fire behaviour of high strength self-consolidating concrete filled steel tubular stub columns. Journal of constructional steel research 2009; 65(10-11):1995-2010.

[4] Wang ZH, Au SK, Tan KH. Heat transfer analysis using a Green's function approach for uniformly insulated steel members subjected to fire. Engineering Structures 2005; 27(10): 1551-1562.

[5] Wang ZH, Tan KH. Green's function solution for transient heat conduction in concrete filled steel CHS subjected to fire. Engineering Structures 2006; 28(11): 1574-1585.

[6] Lie TT. Fire resistance of circular steel columns filled with bar-reinforced concrete. Journal of Structural Engineering-ASCE 1994; 120(5):1489-1509.

[7] Dusinberre, G.M. Heat transfer calculations by finite differences. International Textbook Co., Scranton, Pa. 1961.

[8] Espinos A., Romero M.L., Hospitaler A. Simple calculation model for evaluating the fire resistance of unreinforced concrete filled tubular columns. Engineering Structures 2012; 42: 231-244. 
[9] Yu M., Zha X., Ye J., Wang B. A unified method for calculating the fire resistance of solid and hollow concrete filled steel tube columns based on average temperature. Engineering Structures 2014; 71: 12-22.

[10] ISO (International Standards Organization). ISO 834: Fire resistance tests, elements of building construction. Switzerland: International Standards Organisation; 1980.

[11] CEN. EN 1991-1-2, Eurocode 1: Actions on structures, Part 1.2: General actions Actions on structures exposed to fire. Brussels, Belgium: Comité Européen de Normalisation; 2002.

[12] Ibañez C., Romero M.L., Hospitaler A. Fiber beam model for fire response simulation of axially loaded concrete filled tubular columns. Engineering Structures 2013; 56: 182-193

[13] Romero M.L., Moliner V., Espinos A., Ibañez C., Hospitaler A. Fire behavior of axially loaded slender high strength concrete filled tubular columns. Journal of Constructional Steel Research 2011; 67: 1953-1965.

[14] Moliner V., Espinos A., Romero M.L., Hospitaler A. Fire behavior of eccentrically loaded slender high strength concrete filled tubular columns. Journal of Constructional Steel Research 2013. 83: 137-146.

[15] Lie TT, Chabot M. Experimental studies on the fire resistance of hollow steel columns filled with plain concrete. Internal report No. 611. Ottawa, Canada: Institute for Research in Construction, National Research Council of Canada (NRCC); 1992. 
[16] ASTM. Standard ASTM E119-88: Standard methods of fire test of building construction and materials. Philadelphia, Pa: American Society for Testing and Materials; 1990.

[17] CEN. EN 1992-1-2, Eurocode 2: Design of concrete structures, Part 1.2: General rules - Structural fire design. Brussels, Belgium: Comité Européen de Normalisation; 2004.

[18] Kodur V.K.R, Sultan M.A. Effect of temperature on thermal properties of highstrength concrete. Journal of Materials in Civil Engineering 2003; 15(2):101-107.

[19] Kodur V.K.R, Lie TT. Fire resistance of circular steel columns filled with fiberreinforced concrete. Journal of Structural Engineering-ASCE 1996; 122(7):776782.

[20] Lie TT, Kodur V.K.R. Effect of temperature on thermal and mechanical properties of steel fiber-reinforced concrete. Internal report No. 695. Ottawa, Canada: Institute for Research in Construction, National Research Council of Canada (NRCC); 1995.

[21] CEN. EN 1993-1-2, Eurocode 3: Design of steel structures, Part 1.2: General rules - Structural fire design. Brussels, Belgium: Comité Européen de Normalisation; 2005.

[22] Ding J, Wang YC. Realistic modelling of thermal and structural behavior of unprotected concrete filled tubular columns in fire. Journal of Constructional Steel Research 2008; 64:1086-1102.

[23] Wickström, U. 1986, "A very simple method for estimating temperature in fire exposed concrete structures." Fire Technology Technical report SP-RAPP 1986, 46, Swedish National Testing Institute, pp. 186-194. 
[24] CEN-TC-250-Horizontal Group Fire. Document 99/130. Eurocodes-Fire Parts. Proposal for a methodology to check the accuracy of assessment methods.. November 1999

[25] CEN. EN 1994-1-1, Eurocode 4: Design of composite steel and concrete structures, Part 1.1: General rules and rules for buildings. Brussels, Belgium: Comité Européen de Normalisation; 2004. 


\section{LIST OF FIGURE CAPTIONS}

Fig. 1. CFT column. Discretization of the section for thermal analysis.

Fig. 2. Detail of the section. Gap conductance at steel-concrete boundary.

Fig. 3. Comparison between measured and thermal model predicted temperatures with different steel-concrete boundary model: gap conductance versus perfect contact.

Fig. 4. Comparison of temperatures at failure.

Fig. 5. Temperature profile of a longitudinal section of a CFT column.

Fig. 6. Comparison of the predicted temperatures given by the equations proposed and the values generated in the thermal parametric analysis.

Fig. 7. Comparison of test temperatures with temperatures calculated by thermal model and proposed equations for one of the specimens analyzed (C-09).

Fig. 8. Cross-section schemes for CFT columns used for calculation.

Fig. 9. Comparison of predicted and numerical values of the concrete core equivalent cross-section radius.

Fig. 10. Relative error. Comparison between the results of the calculation proposal and the numerical simulations.

Fig. 11. Comparison between the proposed method and numerical simulations.

Fig. 12. Comparison between predicted loads and tests loads. 
Ibañez C, Aguado JV, Romero ML, Espinos A, Hospitaler A. Fire design method for concrete filled tubular columns based on equivalent concrete core cross-section. Fire Safety Journal. 2015; 78:10-23.

doi: 10.1016/j.firesaf.2015.07.009

\section{LIST OF TABLE CAPTIONS}

Table 1 . Tests by the authors [13] [14] .

Table 2. Tests from experimental programs found in literature [15].

Table 3. Studied variables in the thermo-mechanical parametric analysis and adopted values. 


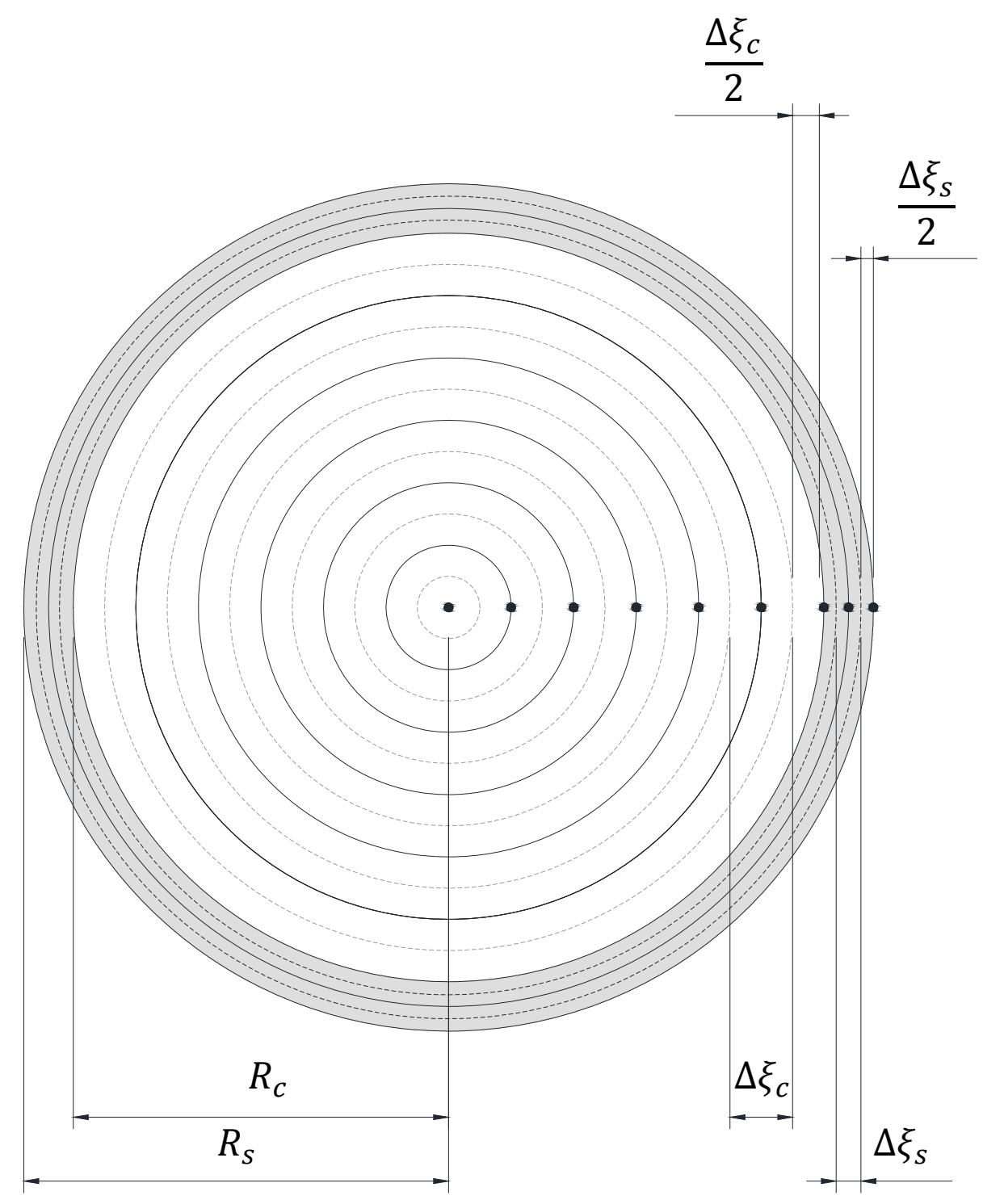

Fig. 1. CFT column. Discretization of the section for thermal analysis. 


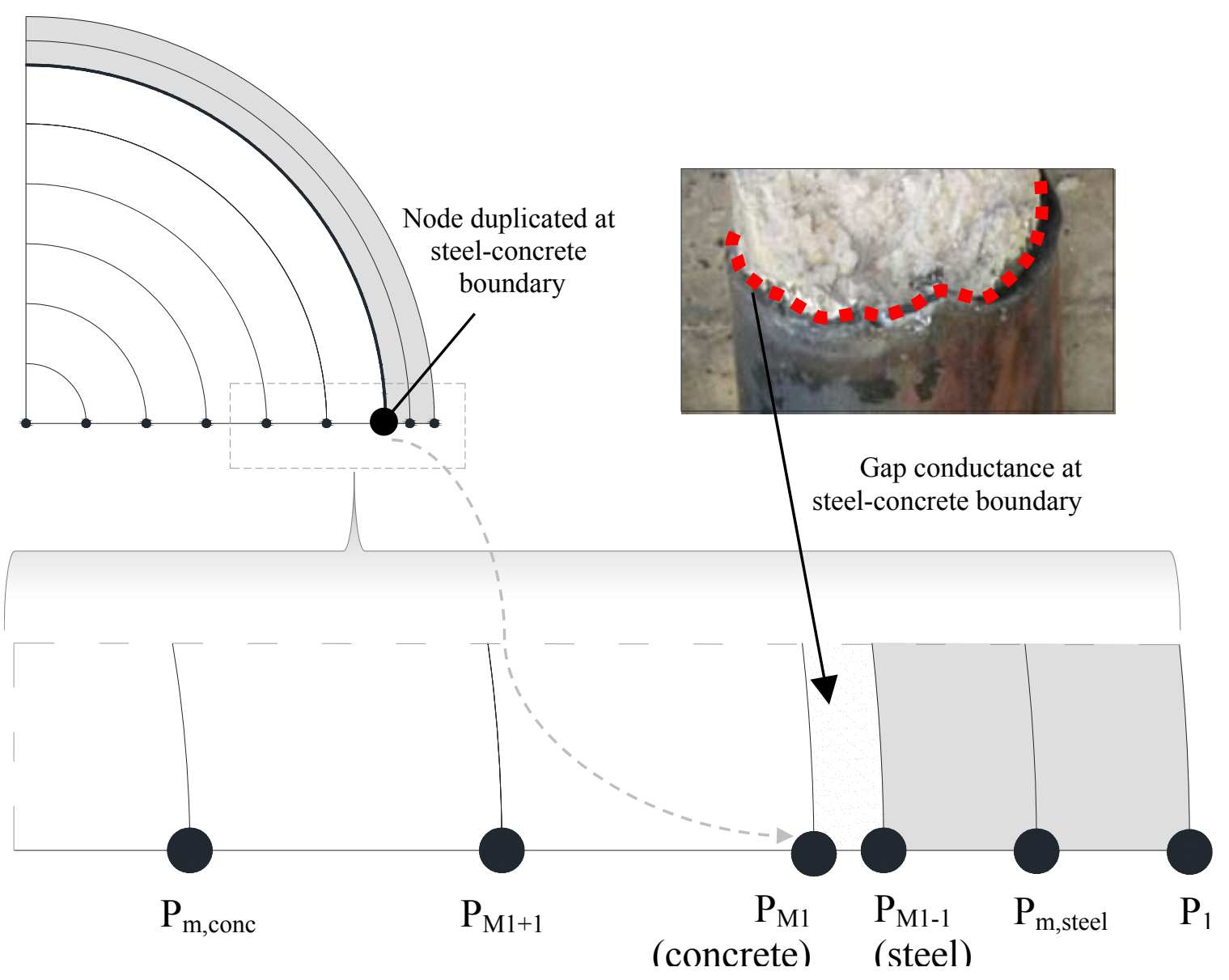

Fig. 2. Detail of the section. Gap conductance at steel-concrete boundary. 


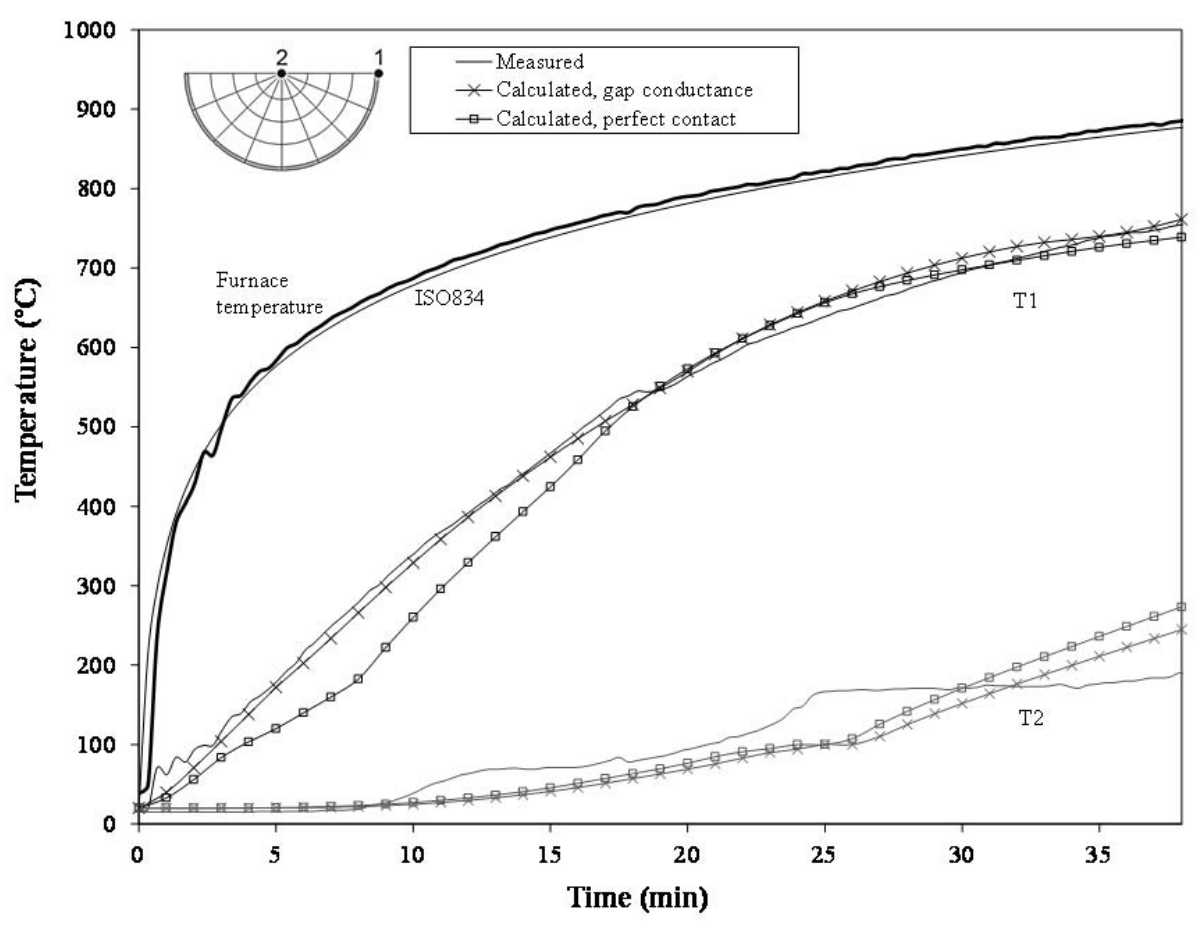

(a) Column C-159-6-3-80-0-20

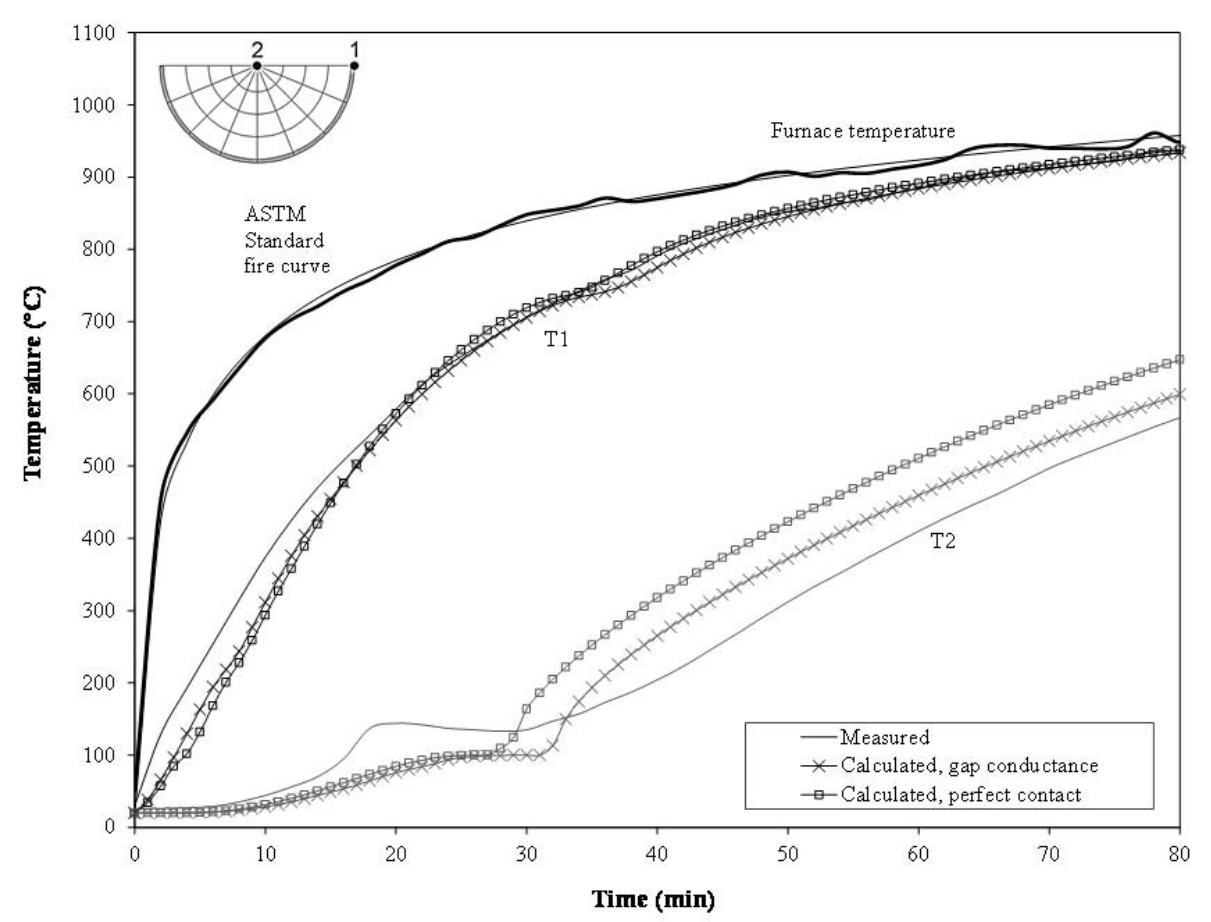

(b) Column C-31

Fig. 3. Comparison between measured and thermal model predicted temperatures with different steel-concrete boundary model: gap conductance versus perfect contact. 


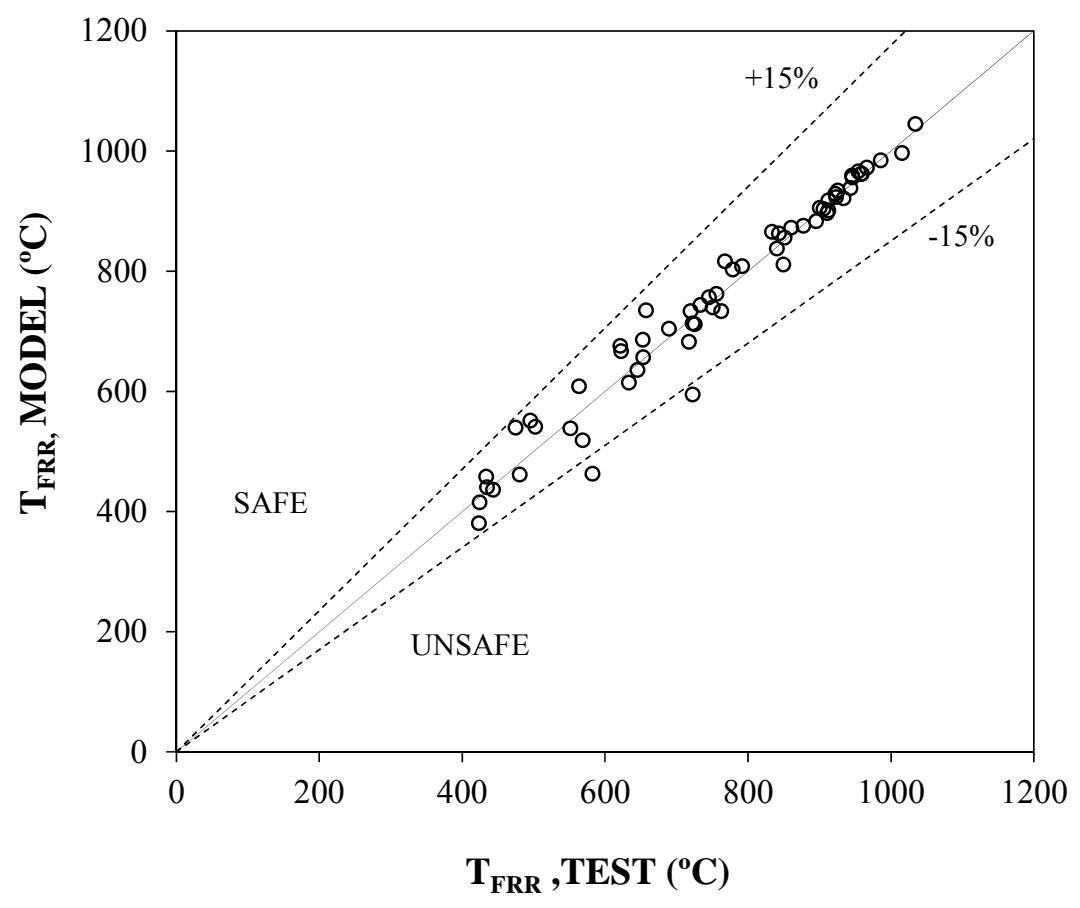

(a) Temperature predicted by the model vs. test temperature

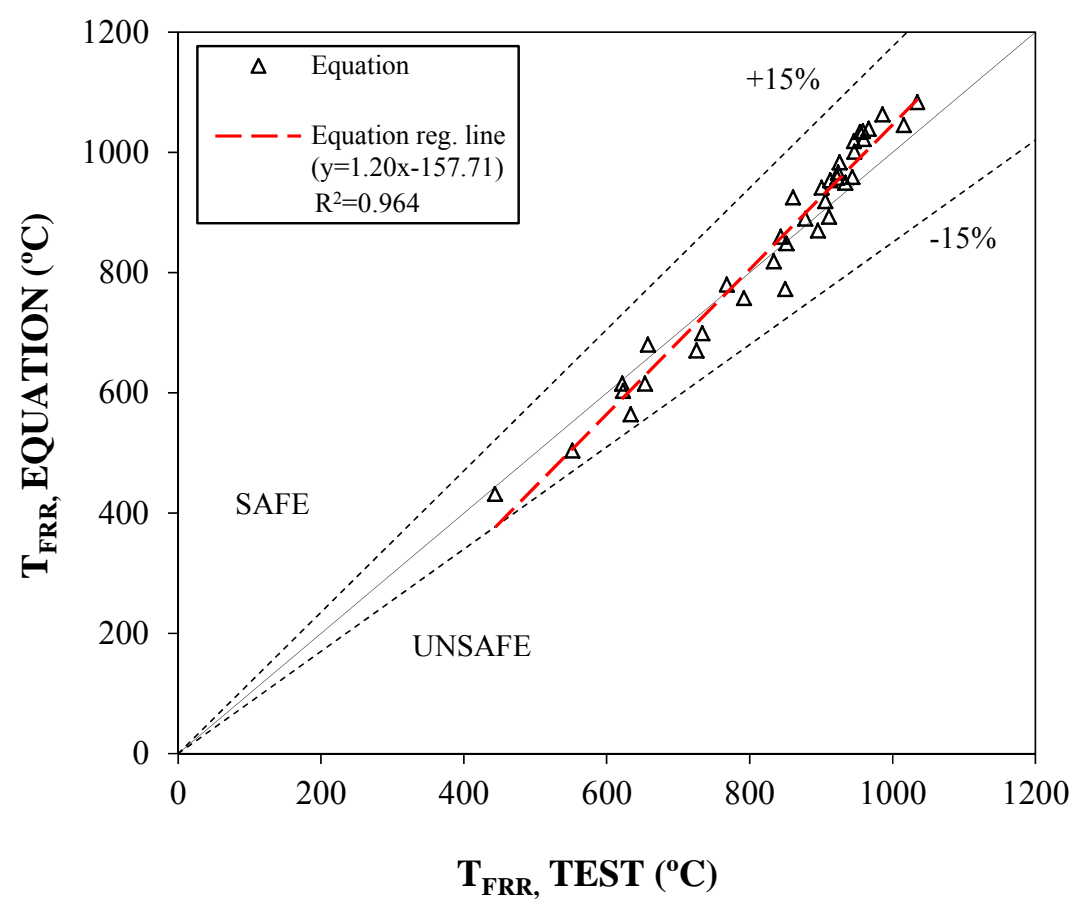

(b) Temperature predicted by the equations vs. test temperature

Fig. 4. Comparison of temperatures at failure. 
Ibañez C, Aguado JV, Romero ML, Espinos A, Hospitaler A. Fire design method for concrete filled tubular columns based on equivalent concrete core cross-section. Fire Safety Journal. 2015; 78:10-23.

doi: 10.1016/j.firesaf.2015.07.009

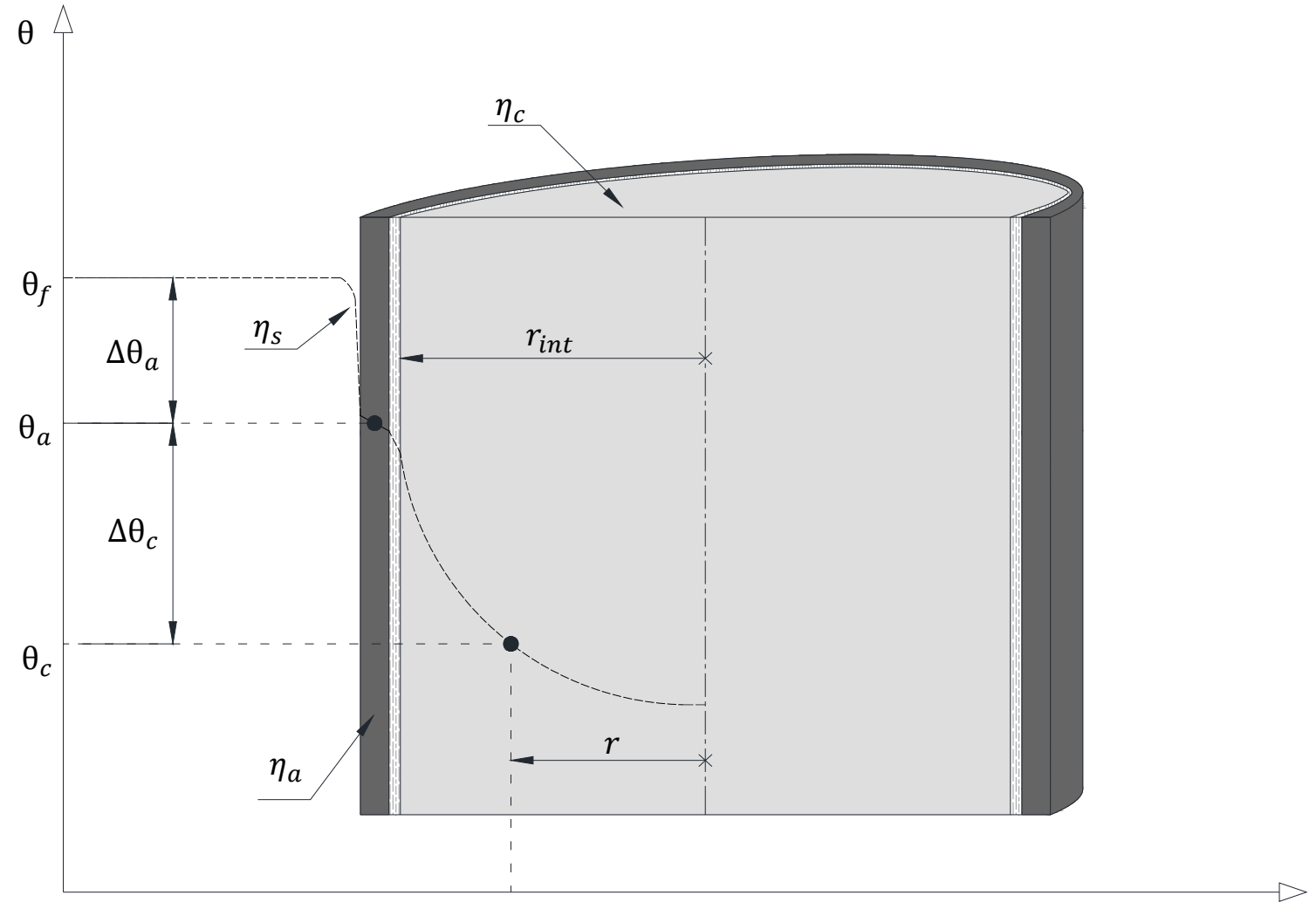

Position

Fig. 5. Temperature profile of a longitudinal section of a CFT column. 


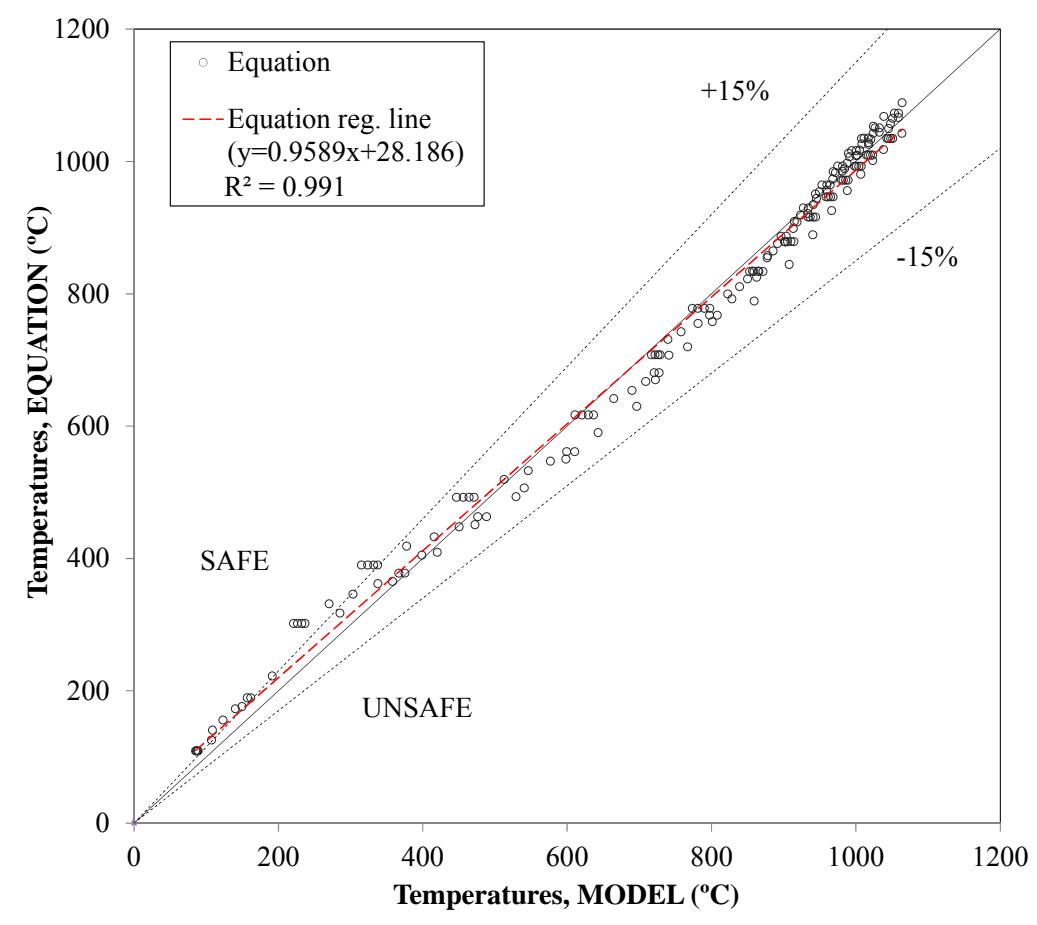

(a) Steel tube temperatures

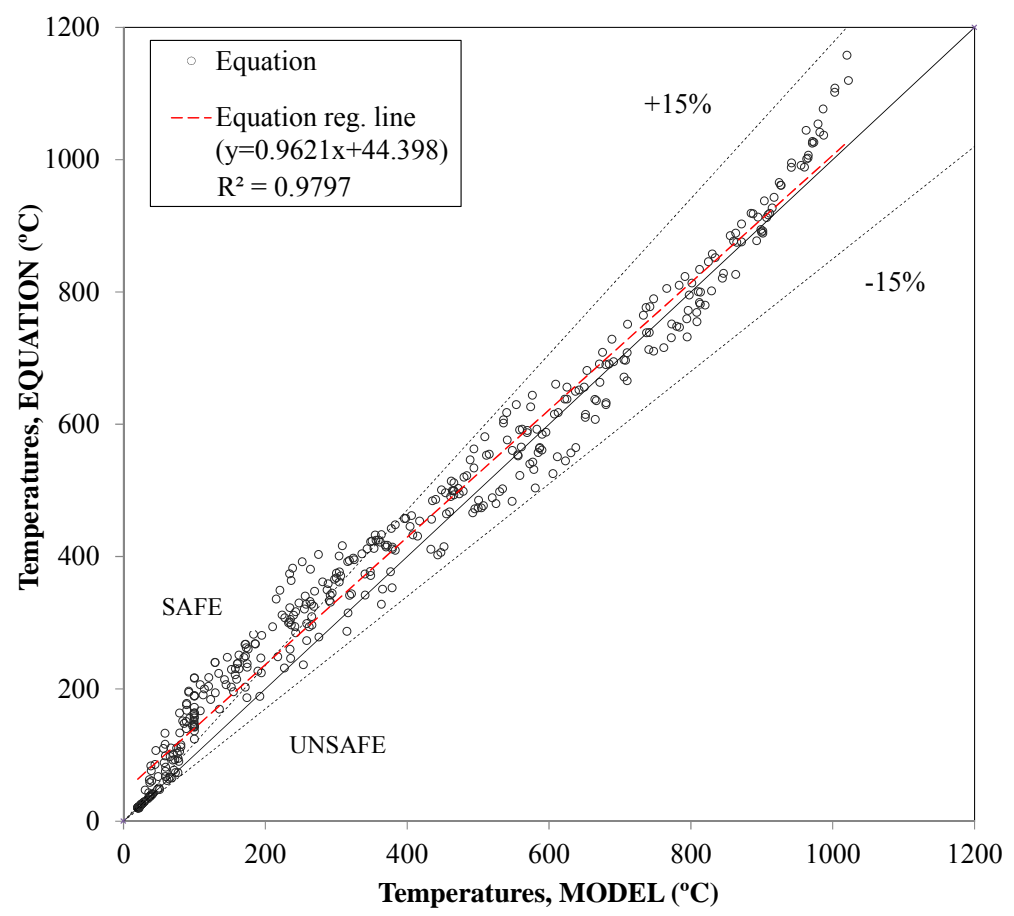

(b) Concrete core temperatures

Fig. 6. Comparison of the predicted temperatures given by the equations proposed and the values generated in the thermal parametric analysis. 


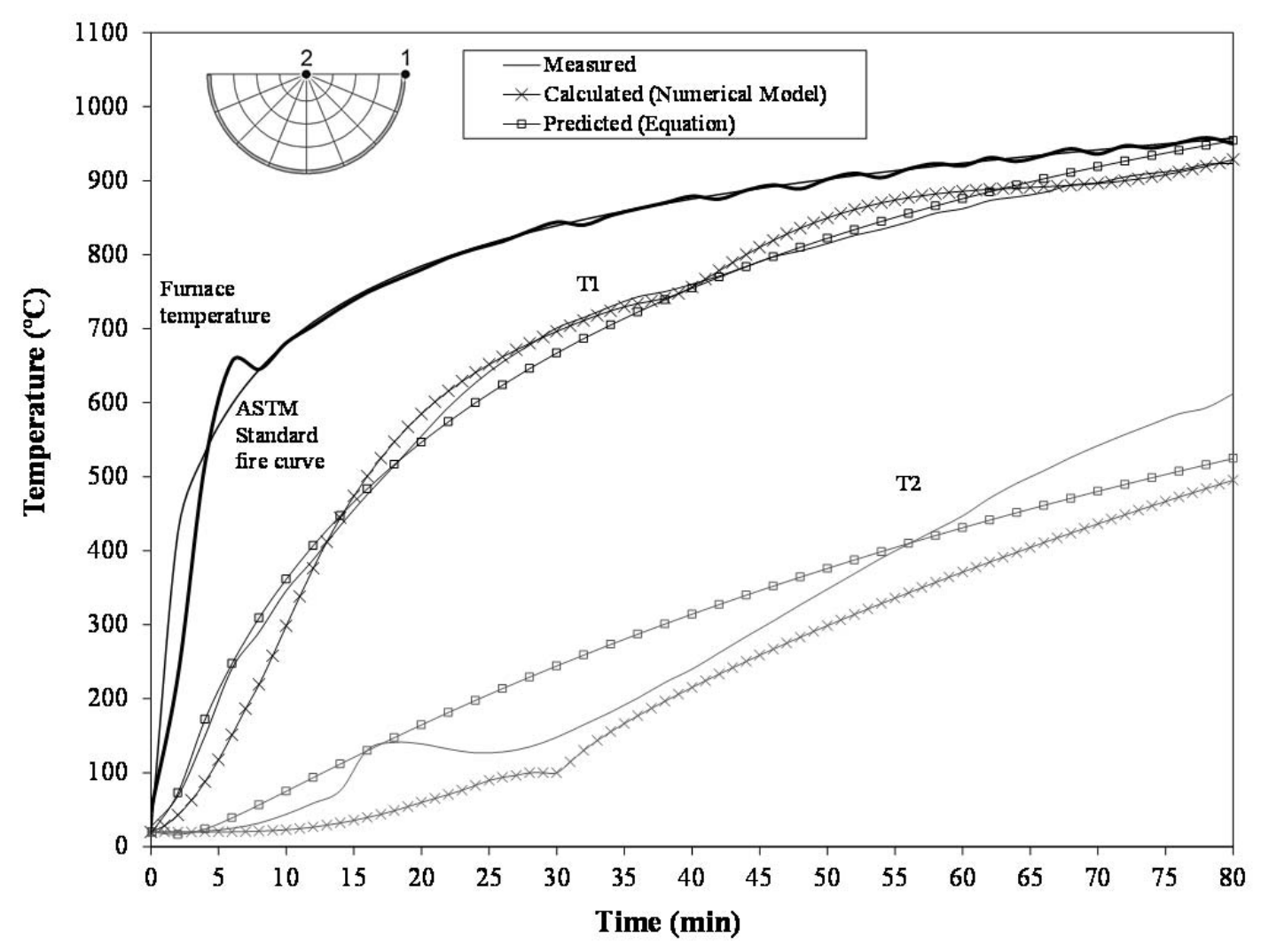

Fig. 7. Comparison of test temperatures with temperatures calculated by thermal model and proposed equations for one of the specimens analyzed (C-09). 


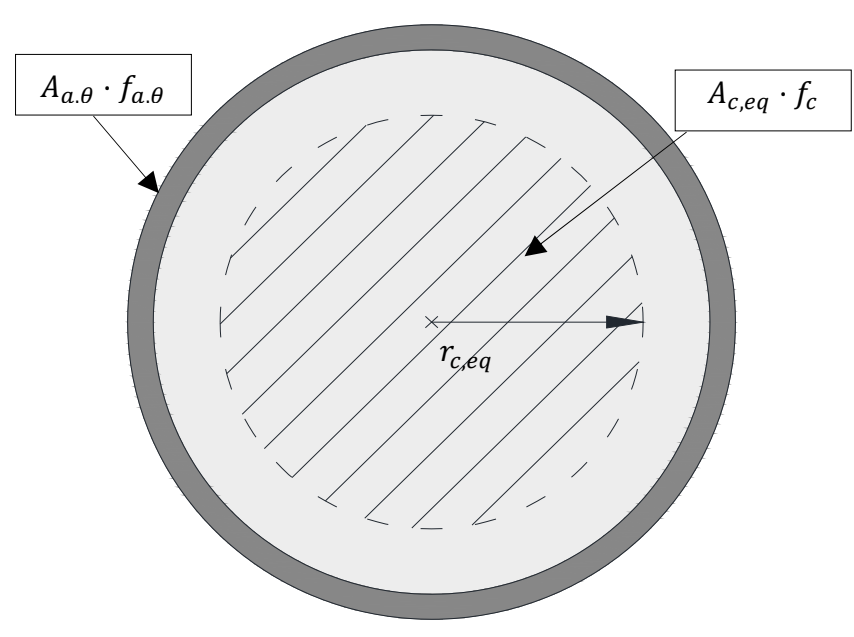

(a) Cross-section adopted by the proposed method. Striped area represents the equivalent concrete core cross-section at room temperature given by $r_{c, e q}$

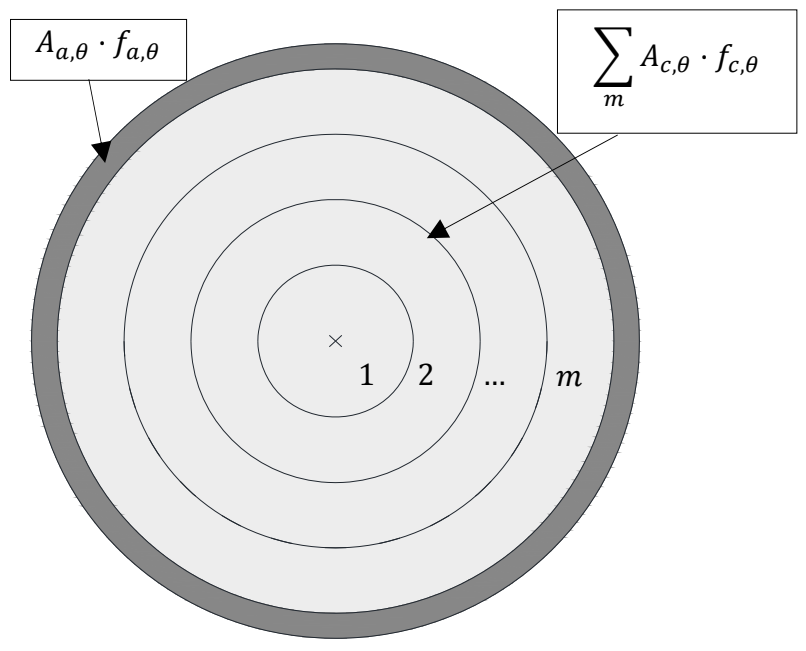

(b) Layer discretization of the cross-section according to EN 1994-1-2 [1] for design purposes.

Fig. 8. Cross-section schemes for CFT columns used for calculation. 


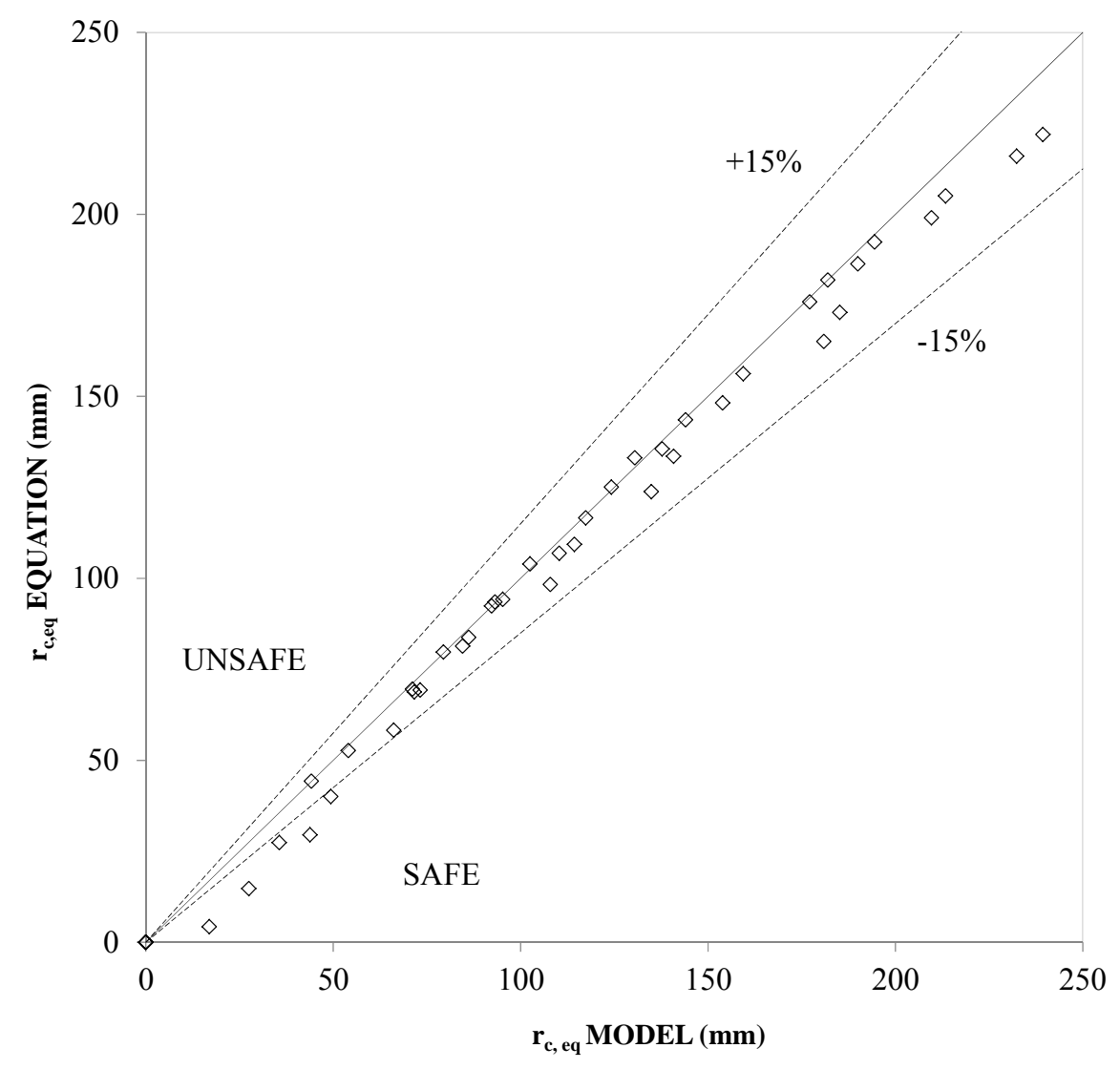

Fig. 9. Comparison of predicted and numerical values of the concrete core equivalent cross-section radius. 


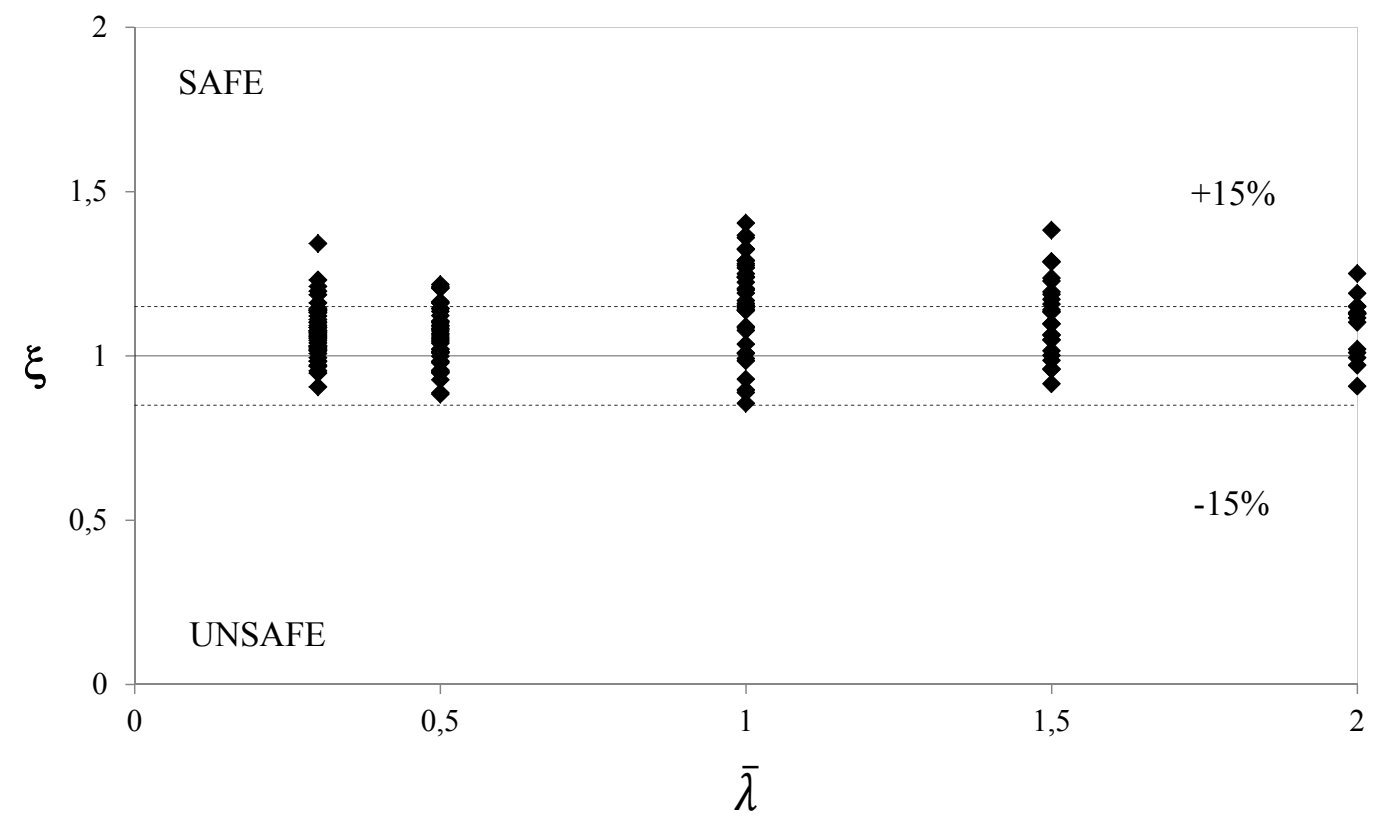

Fig. 10. Relative error. Comparison between the results of the calculation proposal and the numerical simulations. 


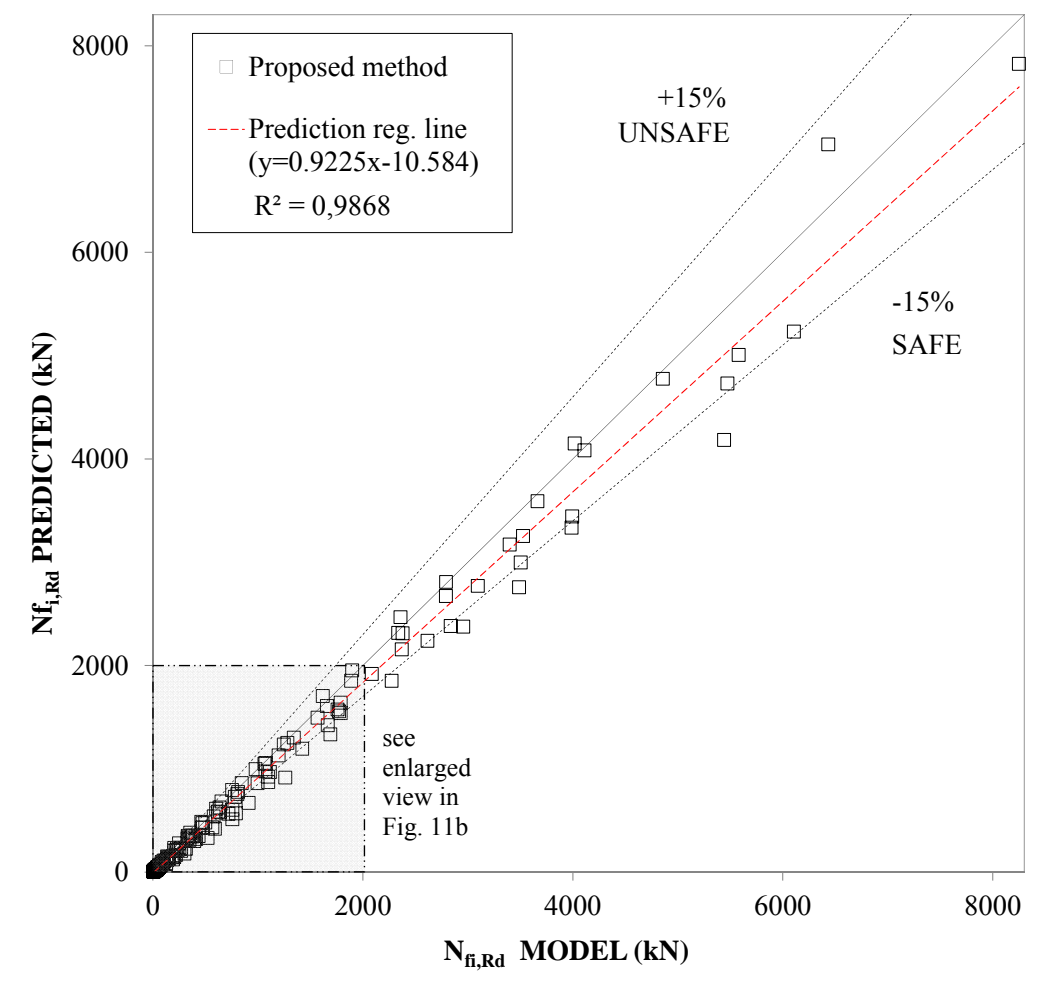

(a) Proposed method predictions vs. model results

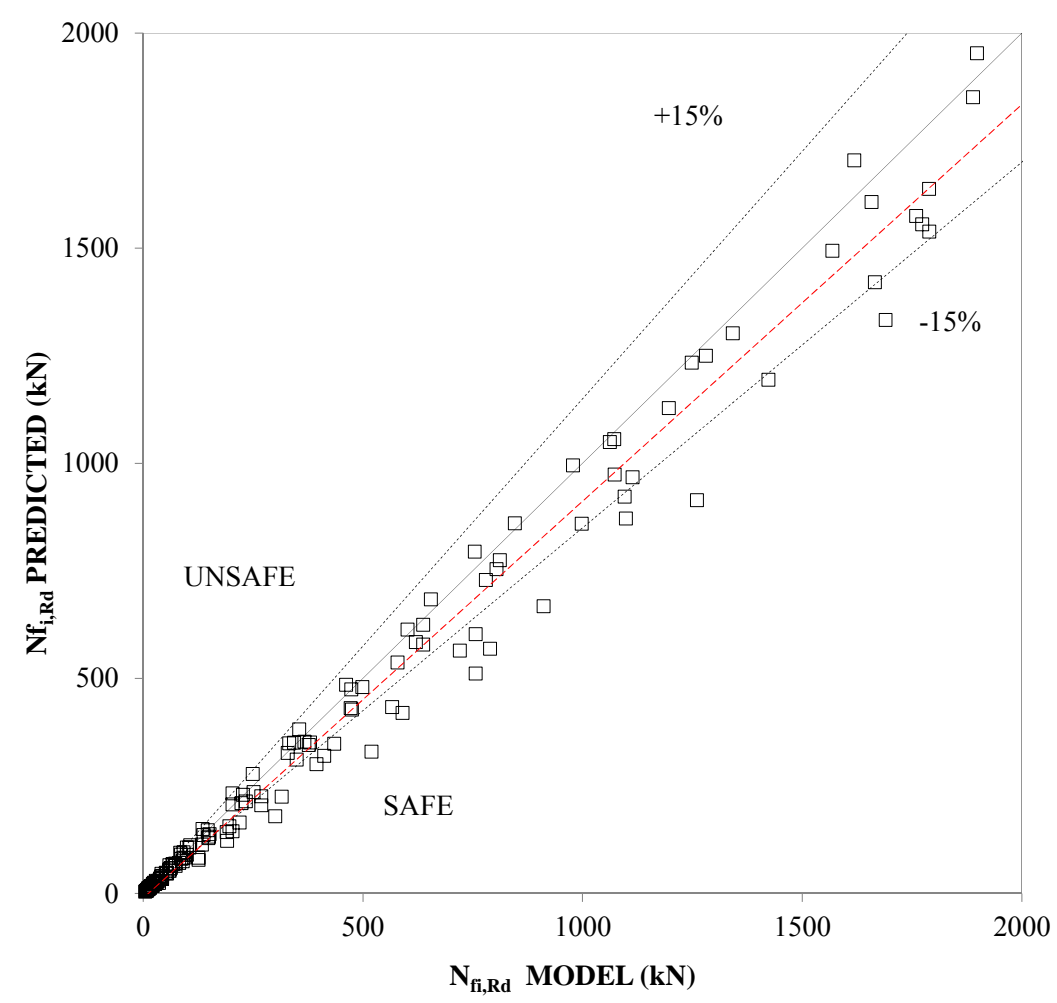

(b) Enlarged view of shaded area in Fig11 a.

Fig. 11. Comparison between the proposed method and numerical simulations. 


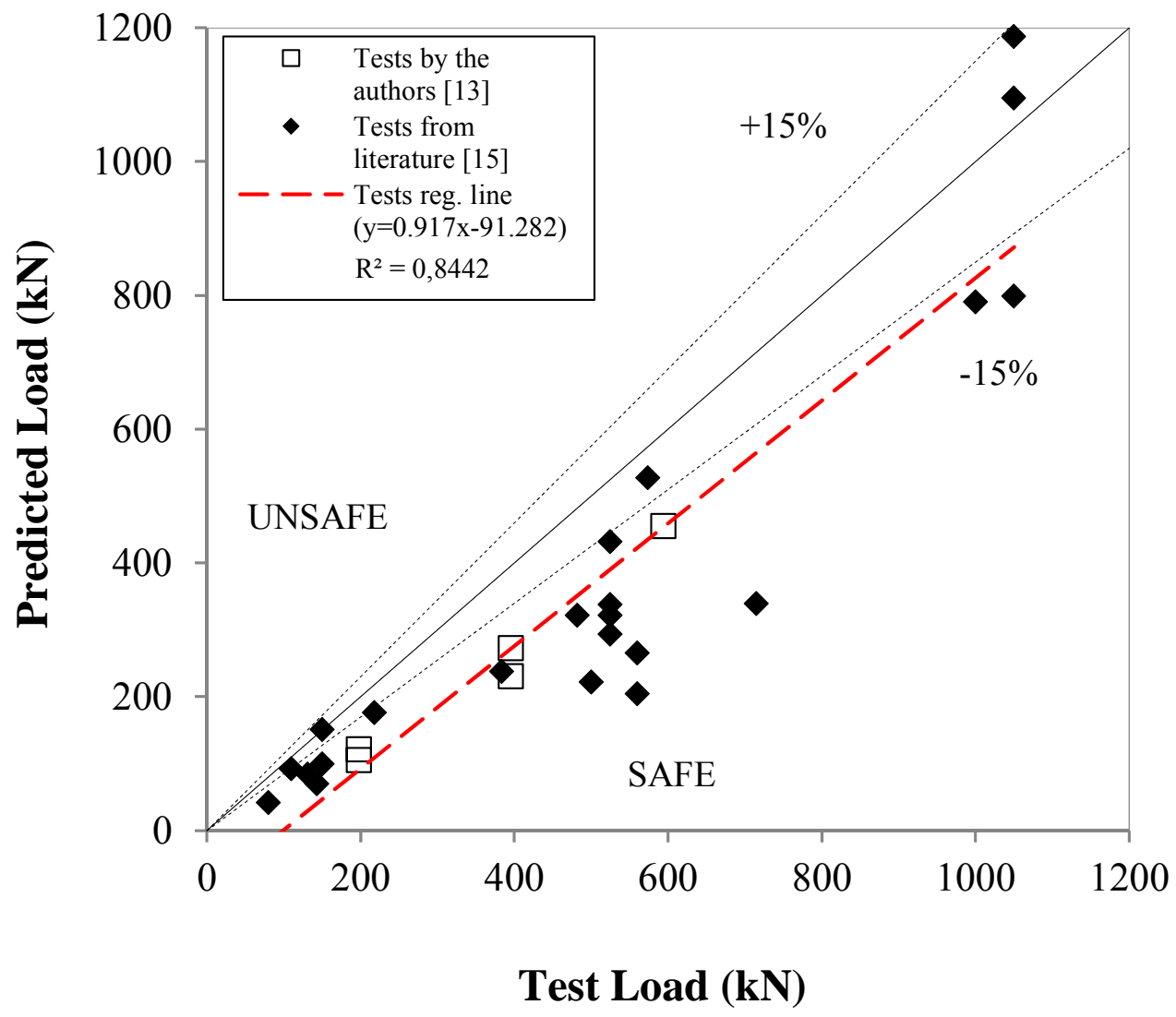

Fig. 12. Comparison between predicted loads and tests loads. 
Table 1 . Tests by the authors [13][14] .

\begin{tabular}{|c|c|c|c|c|c|c|c|c|c|c|}
\hline $\begin{array}{l}\text { Column } \\
\text { Name }\end{array}$ & $\begin{array}{c}D \\
(\mathrm{~mm})\end{array}$ & $\begin{array}{c}t \\
(\mathrm{~mm})\end{array}$ & $\begin{array}{c}f_{y} \\
\left(\mathrm{~N} / \mathrm{mm}^{2}\right)\end{array}$ & $\begin{array}{c}f_{c} \\
\left(\mathrm{~N} / \mathrm{mm}^{2}\right)\end{array}$ & $(\mathrm{kN})$ & $\mu$ & $\begin{array}{l}F R R \\
\text { (min) }\end{array}$ & $\begin{array}{l}T_{\text {FRR }} \text { Test } \\
\left({ }^{\circ} \mathbf{C}\right)\end{array}$ & $\begin{array}{c}T_{\text {FRR }} \text { MODEL } \\
\left({ }^{\circ} \mathbf{C}\right)\end{array}$ & 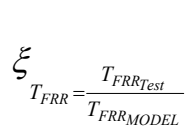 \\
\hline C159-6-3-30-0-20 & 159 & 6 & 337.80 & 35.75 & 198 & 0.2 & 42 & 850 & 810 & 1.05 \\
\hline C159-6-3-30-0-40 & 159 & 6 & 337.80 & 28.55 & 396 & 0.4 & 25 & 654 & 656 & 1.00 \\
\hline C159-6-3-30-0-60 & 159 & 6 & 337.80 & 34.05 & 594 & 0.6 & 14 & 583 & 462 & 1.26 \\
\hline C159-6-3-80-0-20 & 159 & 6 & 341.40 & 71.14 & 335 & 0.2 & 37 & 756 & 761 & 0.99 \\
\hline C159-6-3-80-0-40 & 159 & 6 & 341.40 & 69.00 & 670 & 0.4 & 11 & 424 & 380 & 1.12 \\
\hline RC159-6-3-30-0-20 & 159 & 6 & 337.80 & 23.90 & 229 & 0.2 & 43 & 768 & 816 & 0.94 \\
\hline RC159-6-3-30-0-40 & 159 & 6 & 337.80 & 30.00 & 458 & 0.4 & 30 & 726 & 711 & 1.02 \\
\hline RC159-6-3-30-0-60 & 159 & 6 & 337.80 & 33.70 & 687 & 0.6 & 13 & 444 & 436 & 1.02 \\
\hline RC159-6-3-80-0-20 & 159 & 6 & 337.80 & 69.03 & 343 & 0.2 & 64 & 913 & 900 & 1.01 \\
\hline RC159-6-3-80-0-40 & 159 & 6 & 337.80 & 77.00 & 720 & 0.4 & 18 & 496 & 551 & 0.90 \\
\hline FC159-6-3-30-0-20 & 159 & 6 & 337.80 & 28.30 & 198 & 0.2 & 36 & 751 & 739 & 1.02 \\
\hline FC159-6-3-30-0-40 & 159 & 6 & 334.40 & 26.70 & 396 & 0.4 & 22 & 723 & 594 & 1.22 \\
\hline FC159-6-3-80-0-20 & 159 & 6 & 337.80 & 93.62 & 335 & 0.2 & 35 & 763 & 733 & 1.04 \\
\hline FC159-6-3-80-0-40 & 159 & 6 & 334.40 & 90.16 & 670 & 0.4 & 15 & 481 & 461 & 1.04 \\
\hline C159-6-3-30-20-20 & 159 & 6 & 332.03 & 35.83 & 169 & 0.2 & 33 & 734 & 743 & 0.99 \\
\hline C159-6-3-30-20-40 & 159 & 6 & 332.03 & 42.17 & 337 & 0.4 & 17 & 552 & 538 & 1.03 \\
\hline C159-6-3-30-50-20 & 159 & 6 & 332.03 & 73.70 & 272 & 0.2 & 31 & 658 & 735 & 0.90 \\
\hline C159-6-3-30-50-40 & 159 & 6 & 343.63 & 74.64 & 544 & 0.4 & 24 & 623 & 667 & 0.93 \\
\hline C159-6-3-90-20-20 & 159 & 6 & 343.63 & 30.5 & 126 & 0.2 & 35 & 746 & 754 & 0.99 \\
\hline C159-6-3-90-20-40 & 159 & 6 & 365.65 & 38.25 & 253 & 0.4 & 13 & 435 & 438 & 0.99 \\
\hline C159-6-3-90-50-20 & 159 & 6 & 365.65 & 79.13 & 194 & 0.2 & 31 & 720 & 733 & 0.98 \\
\hline C159-6-3-90-50-40 & 159 & 6 & 365.65 & 98.32 & 388 & 0.4 & 17 & 475 & 539 & 0.88 \\
\hline RC159-6-3-30-20-20 & 159 & 6 & 357.22 & 39.00 & 180 & 0.2 & 49 & 834 & 865 & 0.96 \\
\hline RC159-6-3-30-20-40 & 159 & 6 & 357.22 & 40.38 & 360 & 0.4 & 25 & 622 & 675 & 0.92 \\
\hline RC159-6-3-30-50-20 & 159 & 6 & 357.22 & 93.67 & 264 & 0.2 & 40 & 792 & 814 & 0.97 \\
\hline RC159-6-3-30-50-40 & 159 & 6 & 386.38 & 96.00 & 528 & 0.4 & 21 & 634 & 623 & 1.02 \\
\hline RC159-6-3-90-20-20 & 159 & 6 & 386.38 & 31.00 & 140 & 0.2 & 49 & 841 & 835 & 1.01 \\
\hline RC159-6-3-90-20-40 & 159 & 6 & 386.38 & 39.50 & 280 & 0.4 & 25 & 718 & 675 & 1.06 \\
\hline RC159-6-3-90-50-20 & 159 & 6 & 315.22 & 92.97 & 204 & 0.2 & 41 & 779 & 802 & 0.97 \\
\hline RC159-6-3-90-50-40 & 159 & 6 & 315.22 & 91.87 & 407 & 0.4 & 17 & 503 & 541 & 0.93 \\
\hline FC159-6-3-30-20-20 & 159 & 6 & 315.22 & 34.67 & 169 & 0.2 & 32 & 723 & 713 & 1.01 \\
\hline FC159-6-3-30-20-40 & 159 & 6 & 337.77 & 31.50 & 337 & 0.4 & 18 & 569 & 518 & 1.10 \\
\hline FC159-6-3-30-50-20 & 159 & 6 & 337.77 & 87.12 & 272 & 0.2 & 31 & 690 & 710 & 0.97 \\
\hline FC159-6-3-30-50-40 & 159 & 6 & 337.77 & 83.04 & 544 & 0.4 & 25 & 646 & 644 & 1.00 \\
\hline FC159-6-3-90-20-20 & 159 & 6 & 318.64 & 33.00 & 126 & 0.2 & 24 & 564 & 599 & 0.94 \\
\hline FC159-6-3-90-20-40 & 159 & 6 & 318.64 & 37.65 & 253 & 0.4 & 14 & 425 & 407 & 1.04 \\
\hline FC159-6-3-90-50-20 & 159 & 6 & 318.64 & 96.99 & 194 & 0.2 & 30 & 653 & 685 & 0.95 \\
\hline FC159-6-3-90-50-40 & 159 & 6 & 326.39 & 92.78 & 388 & 0.4 & 16 & 434 & 458 & 0.95 \\
\hline & & & & & & & & \multicolumn{2}{|c|}{ Mean } & 1.00 \\
\hline & & & & & & & & \multicolumn{2}{|c|}{ Standard deviation } & 0.01 \\
\hline
\end{tabular}


Table 2. Tests from experimental programs found in literature [15].

\begin{tabular}{|c|c|c|c|c|c|c|c|c|c|c|}
\hline $\begin{array}{c}\text { Column } \\
\text { Name }\end{array}$ & $\begin{array}{c}D \\
(\mathbf{m m}) \\
\end{array}$ & $\begin{array}{c}t \\
(\mathrm{~mm}) \\
\end{array}$ & $\begin{array}{c}f_{y} \\
\left(\mathrm{~N} / \mathbf{m m}^{2}\right) \\
\end{array}$ & $\begin{array}{c}f_{c} \\
\left(\mathrm{~N} / \mathbf{m m}^{2}\right)\end{array}$ & $\begin{array}{c}N \\
(\mathbf{k N})\end{array}$ & $\mu$ & $\begin{array}{l}F R R \\
\text { (min) }\end{array}$ & $\begin{array}{l}T_{F R R_{\text {Test }}} \\
\left({ }^{\circ} \mathbf{C}\right) \\
\end{array}$ & $\begin{array}{c}T_{F R R} \text { MODEL } \\
\left({ }^{\circ} \mathbf{C}\right) \\
\end{array}$ & $\xi_{T_{F R R}=\frac{T_{F R R_{\text {Test }}}}{T_{T_{F R R_{M O D E L}}}}}$ \\
\hline C-02 & 141.3 & 6.55 & 350 & 33.1 (sil) & 110 & 0.12 & 55 & 852 & 855 & 1.00 \\
\hline C-04 & 141.3 & 6.55 & 350 & 31.0 (sil) & 131 & 0.14 & 57 & 844 & 862 & 0.98 \\
\hline $\mathrm{C}-05$ & 168.3 & 4.78 & 350 & 32.7 (sil) & 150 & 0.16 & 76 & 913 & 917 & 1.00 \\
\hline C-06 & 168.3 & 4.78 & 350 & 32.7 (sil) & 150 & 0.19 & 60 & 878 & 875 & 1.00 \\
\hline C- 08 & 168.3 & 4.78 & 350 & 35.5 (sil) & 218 & 0.23 & 56 & 896 & 882 & 1.02 \\
\hline C-09 & 168.3 & 6.35 & 350 & 35.4 (sil) & 150 & 0.13 & 81 & 923 & 928 & 0.99 \\
\hline $\mathrm{C}-11$ & 219.1 & 4.78 & 350 & 31.0 (sil) & 492 & 0.35 & 80 & 924 & 923 & 1.00 \\
\hline $\mathrm{C}-13$ & 219.1 & 4.78 & 350 & 32.3 (sil) & 384 & 0.27 & 102 & 960 & 961 & 1.00 \\
\hline $\mathrm{C}-15$ & 219.1 & 8.18 & 350 & 31.9 (sil) & 525 & 0.28 & 73 & 906 & 903 & 1.00 \\
\hline $\mathrm{C}-17$ & 219.1 & 8.18 & 350 & 31.7 (sil) & 525 & 0.26 & 82 & 934 & 921 & 1.01 \\
\hline $\mathrm{C}-20$ & 273.1 & 5.56 & 350 & 28.6 (sil) & 574 & 0.26 & 112 & 959 & 961 & 1.00 \\
\hline $\mathrm{C}-21$ & 273.1 & 5.56 & 350 & 29.0 (sil) & 525 & 0.23 & 133 & 986 & 984 & 1.00 \\
\hline $\mathrm{C}-22$ & 273.1 & 5.56 & 350 & 27.2 (sil) & 1000 & 0.45 & 70 & 861 & 871 & 0.99 \\
\hline $\mathrm{C}-23$ & 273.1 & 12.70 & 350 & 27.4 (sil) & 525 & 0.13 & 143 & 1016 & 996 & 1.02 \\
\hline $\mathrm{C}-31$ & 141.3 & 6.55 & 300 & $30.2(\mathrm{cal})$ & 80 & 0.09 & 82 & 944 & 937 & 1.01 \\
\hline $\mathrm{C}-32$ & 141.3 & 6.55 & 300 & $34.8(\mathrm{cal})$ & 143 & 0.17 & 64 & 911 & 896 & 1.02 \\
\hline $\mathrm{C}-34$ & 219.1 & 4.78 & 300 & 35.4 (cal) & 500 & 0.36 & 111 & 967 & 971 & 1.00 \\
\hline $\mathrm{C}-35$ & 219.1 & 4.78 & 300 & 42.7 (cal) & 560 & 0.36 & 108 & 955 & 965 & 0.99 \\
\hline $\mathrm{C}-37$ & 219.1 & 8.18 & 350 & 28.7 (cal) & 560 & 0.25 & 102 & 947 & 955 & 0.99 \\
\hline C-40 & 273.1 & 6.35 & 350 & 46.5 (cal) & 1050 & 0.37 & 106 & 946 & 959 & 0.99 \\
\hline C-41 & 273.1 & 6.35 & 350 & 50.7 (cal) & 1050 & 0.37 & 76 & 901 & 905 & 1.00 \\
\hline C-42 & 273.1 & 6.35 & 350 & $55.4(\mathrm{cal})$ & 1050 & 0.35 & 90 & 926 & 933 & 0.99 \\
\hline C-44 & 273.1 & 6.35 & 350 & 38.7 (cal) & 715 & 0.27 & 178 & 1035 & 1045 & 0.99 \\
\hline & & & & & & & & \multicolumn{2}{|c|}{ Mean } & 1.00 \\
\hline & & & & & & & & \multicolumn{2}{|c|}{ Standard deviation } & 0.08 \\
\hline
\end{tabular}


Table 3. Studied variables in the thermo-mechanical parametric analysis and adopted values.

\begin{tabular}{c|cccc}
\hline $\begin{array}{c}\text { Studied } \\
\text { variables }\end{array}$ & $\begin{array}{c}\boldsymbol{D} \\
(\mathbf{m m})\end{array}$ & $\begin{array}{c}\boldsymbol{t} \\
(\mathbf{m m})\end{array}$ & $\bar{\lambda}$ & $\begin{array}{c}\boldsymbol{R} \\
(\mathbf{m i n})\end{array}$ \\
\hline & 139.7 & $3.2 ; 12.5$ & $0.3 ; 0.5 ; 1 ; 1.5 ; 2$ & \\
& 193.7 & $5 ; 16$ & $0.3 ; 0.5 ; 1 ; 1.5 ; 2$ & \\
Adopted & 273 & $5 ; 16$ & $0.3 ; 0.5 ; 1 ; 1.5$ & $30 ; 60 ; 90 ; 120$ \\
values & 323.9 & $6.3 ; 16$ & $0.3 ; 0.5 ; 1$ & \\
& 406.4 & $8 ; 16$ & $0.3 ; 0.5 ; 1$ & \\
& 508 & $10 ; 16$ & $0.3 ; 0.5$ & \\
\hline
\end{tabular}

